\title{
An overview on biofuel and biochemical production by photosynthetic microorganisms with understanding of the metabolism and by metabolic engineering together with efficient cultivation and downstream processing
}

\author{
Dayanidhi Sarkar ${ }^{1}$ and Kazuyuki Shimizu 2,3* $^{3 *}$
}

\begin{abstract}
Biofuel and biochemical production by photosynthetic microorganisms such as cyanobacteria and algae is attractive to improve energy security and to reduce $\mathrm{CO}_{2}$ emission, contributing to the environmental problems such as global warming. Although biofuel production by photosynthetic microorganisms is called as the third generation biofuels, and significant innovation is necessary for the feasibility in practice, these fuels are attractive due to renewable and potentially carbon neutral resources. Moreover, photosynthetic microorganisms are attractive since they can grow on non-arable land and utilize saline and wastewater streams. Highly versatile and genetically tractable photosynthetic microorganisms need to capture solar energy and convert atmospheric and waste $\mathrm{CO}_{2}$ to high-energy chemical products. Understanding of the metabolism and the efficient metabolic engineering of the photosynthetic organisms together with cultivation and separation processes as well as increased $\mathrm{CO}_{2}$ assimilation enables the enhancement of the feasibility of biofuel and biochemical production.
\end{abstract}

Keywords: Microalgae; Cyanobacteria; Biofuels; Metabolic engineering; $\mathrm{CO}_{2}$ fixation; Metabolic regulation

\section{Background}

International Panel on Climate Change (IPCC) keeps warning the global society on global warming caused by green-house gases such as $\mathrm{CO}_{2}$ based on the accumulating data and the reliable prediction model. IPCC asks world societies to make decisions to invest for the reduction of $\mathrm{CO}_{2}$ emissions mostly caused by human activities. This may be also considered from the point of view of future cost caused by the severe climate change due to global warming. Namely, the global warming may cause serious local climate change as well as the rise in the sea level, which give severe damage to the societies worldwide. In fact, we have often experienced disastrous

\footnotetext{
* Correspondence: shimi@bio.kyutech.ac.jp

${ }^{2}$ Kyushu Institute of Technology, lizuka, Fukuoka 820-8502, Japan ${ }^{3}$ Institute of Advanced Bioscience, Keio University, Tsuruoka, Yamagata 997-0017, Japan

Full list of author information is available at the end of the article
}

climate change year by year, and it seems to be more and more severe.

The global carbon cycle has been perturbed by emissions from the combustion of fossil fuels and by changes in land use and land intensity. These perturbations have led to cumulative anthrogenic $\mathrm{CO}_{2}$ emissions of $570 \pm 70$ petagrams carbon since 1750 to 2012 [1]. Seventy percent of these emissions originated from the combustion of fossil fuels [1].

According to the data of International Energy Agency (OECD, 2011), total energy consumption in the world increased more than $78 \%$ over the last three decades. Major usage of fossil fuels causes serious environmental problems worldwide, and much attention has been focused on reducing their usage by alternative clean fuels. Namely, due to the global warming problem caused by the increased use of fossil fuels together with limited amount of fossil fuels and the fluctuating cost caused by unstable political disturbances, alternative renewable 
energy sources have recently been paid much attention [2]. In fact, at the present staggering rate of consumption, the world fossil oil reserves will be exhausted in less than 50 years [3]. Carbon neutral biofuels are needed to replace the petroleum oil which causes global warming caused by the emission of green house gases. Currently, the world consumes about 15 terawatts of energy per year, and only $7.8 \%$ of this is derived from renewable energy sources [4]. Moreover, in comparison with other forms of renewable energy such as wind, tidal, and solar energy, liquid biofuels allow solar energy to be stored and also to be used directly in existing engines and transport infrastructure [5].

Annually, about $5,500 \times 10^{21} \mathrm{~J}$ of solar energy reaches the Earth's atmosphere [6]. Photosynthetic organisms including higher plants, microalgae, and cyanobacteria play the crucial roles of capturing solar energy and storing it as chemical energy [7]. The amount of solar energy currently captured by arable crops is limited by arable land area (about 3.9\% of the Earth's surface area), fresh water (about $1 \%$ of global water), nutrient supply, and solar energy-tobiomass conversion efficiency [8-10]. Terrestrial plants capture $121.7 \times 10^{9}$ metric tons of carbon from the atmosphere each year [11] using solar light and $\mathrm{CO}_{2}$ as the energy and carbon sources. Photosynthesized carbon is then chemically converted to a variety of chemical compounds, and it is attractive to use photosynthetic organisms as green factories for producing carbohydrates, liquid fuels, and pharmaceutical drugs as well as food and feed, thus contributing to the balancing of the atmospheric carbon [12].

The advantages of using photosynthetic microorganisms include the photosynthetic efficiency, location on non-arable land (about 25\% of the Earth's surface), and the use of saline and wastewater source [7], where less than $1 \%$ of the available solar energy flux is converted into chemical energy by photosynthesis [13], and much effort has been focused on the enhancement of photosynthetic carbon fixation.

The so-called first generation biofuels have been produced from corn starch and sugarcane. However, this causes the problem of the so-called 'food and energy issues' as the production scale increases. The second generation biofuels production from lignocellulosic biomass has thus been paid recent attention. However, it requires energy-intensive pretreatment for the degradation of lignocellulosic biomass [14]. The third generation biofuel production from photosynthetic organisms such as cyanobacteria and algae has been also attracted some attention, but the cell growth rate is quite low, and thus the productivity of the metabolites is significantly low [15].

Although the biofuel and biochemical production by photosynthetic organisms has a big hurdle to overcome, it is still highly attractive due to $\mathrm{CO}_{2}$ fixation with sunlight (and water) from environmental protection point of view, and thus contributing to the global warming problem as well. A variety of host organisms such as bacteria, fungi, and microalgae may be considered for the production of biofuels and biochemicals from $\mathrm{CO}_{2}$ with sunlight. Although photosynthetic organisms offer the ability to produce biofuels and biochemicals directly from $\mathrm{CO}_{2}$ and sunlight, significant innovation is inevitable for the process development in relation to largescale cultivation, harvesting, and product separation, since the production rate is significantly low.

The commonly used photosynthetic organisms for biofuel and biochemical production are algae and cyanobacteria $[16,17]$. Microalgae are photosynthetic eukaryotic organisms with size ranging from 1 to $100 \mu \mathrm{m}$, while cyanobacteria are prokaryotic organisms with size ranging from 1 to $10 \mu \mathrm{m}$. Cyanobacteria gave rise to the chloroplasts of eukaryotic algae and also land plants, and they share many features such as the ability to drive photosynthetic water photolysis and thereby contribute to the production of both atmospheric oxygen and reduced organic carbon [7].

Microalgae are unicellular photosynthetic microorganisms that can convert solar energy to chemical energy with efficiency of 10 to 50 times greater than terrestrial plants [18]. Algae have far higher cell growth rates than plants and, therefore, have much smaller footprints for land required for producing energy [19-21]. Many microalgae are rich in oil especially under nitrogenstarved condition, which can be converted to biodiesel using existing technology. The productivity of these photosynthetic microorganisms in converting $\mathrm{CO}_{2}$ into carbon-rich lipids, only a step or two away from biodiesel, significantly exceeds that of agricultural oleaginous crops, without competing for arable land [22]. They require aquatic environments that may vary from freshwater to seawater. Not only do these organisms fix $\mathrm{CO}_{2}$, but they also have the potential to be used for the production of inexpensive bulk chemicals, because the major inputs to the system (light and $\mathrm{CO}_{2}$ ) are essentially free [23]. Microalgae cells contain approximately $50 \%$ of carbon, in which $1.8 \mathrm{~kg}$ of $\mathrm{CO}_{2}$ is fixed by producing $1 \mathrm{~kg}$ of microalgae biomass [19].

Recent studies have reported that Chlorella sp., Scenedesmus sp., and Botryococcus braunii are among the microalgae strains that have shown promising result to bio-mitigate $\mathrm{O}_{2}$ emission with typical $\mathrm{CO}_{2}$ consumption rate of 200 to $1,300 \mathrm{mg} / \mathrm{L} /$ day [24-28]. Successful commercial utilization of microalgae has been established in low-volume, high-value derivatives such as nutritional supplements, antioxidants, cosmetics, natural dyes, and polyunsaturated fatty acids (PUFA) [29].

In the case of plants, it is frequently found that metabolite pools exist in more than one location or that the subcellular location of one or more reactions is uncertain 
[30]. Entire sections of metabolic pathways like glycolysis are duplicated between organelles, particularly the plastid and cytosol, with both being potentially active and carrying flux [31]. The simplest way is to examine metabolites which are formed in only one of the compartments [32-36]. Another method involves the fraction of cellular material prior to metabolite analysis [37]. Unfortunately, even with the supplemental information provided by analyzing compartment-specific metabolites, it may still be difficult to statistically distinguish different configurations of the metabolic map [38].

In the present article, we focus on the typical photosynthetic microorganisms such as algae and cyanobacteria and attempted to make a review on the metabolic regulation, metabolic engineering, and process development with efficient operation for the production of biofuels and chemicals to understand the current status and expect future perspectives.

\section{Candidate photosynthetic microorganisms for biofuel production}

Perhaps the most comprehensive evaluation of algal species has been orchestrated by the US Department of Energy's Aquatic Species Program (ASP) to develop microalgae as a source of biodiesel [29]. Over 3,000 strains of microalgae have been isolated from ponds and seas. Cellular oil content varies with growth phases [39]. The cells of the chlorophyte microalga Parietochloris incise synthesize almost twice as many triacylglycerols (TAGs) in the stationary phase than in the exponential growth phase [40]. Although microalgae have a high level of biodiversity, only a few species can be subjected to genetic manipulation [41]. The algae with the best developed genetic toolbox are the unicellular green microalgae Chlamydomonas reinhardtii [42]. It is a well-established model organism for the study of various cellular processes such as photosynthesis, flagella, starch metabolism, and photobiological production of hydrogen [42]. Like many other algal species, C. reinhardtii can accumulate significant amount of oil when subjected to unfavorable environmental conditions [43-47]. C. reinhardtii has proven to be a useful model organism to study the improvement of biodiesel production by microalgae $[48,49]$. It is unicellular and stays as haploid during most of its life cycle [42], thus it is particularly useful in the context of a forward genetic approach, because the mutant phenotype can be observed during the first generation and does not need to reach a diploid homozygous stage [50]. The freshwater green microalgae $P$ incise enhances not only its production of TAG under nitrogen starvation but also the production of arachidonic acid, a valuable nutraceutical [51]. Green algae including Spirogyra sp. and Chlorococum sp. have been shown to accumulate high levels of polysaccharides both in their complex cell walls and as starch [4]. This starch can be used for bioethanol production. Bioethanol production from algae shows significant potential due to their low percentage of lignin and hemicelluloses as compared to other lignocellulosic plants [52]. Microalgae and cyanobacteria are also able to directly produce biohydrogen through photofermentation in an anaerobic process involving oxidation of ferredoxin by the hydrogenase enzyme [53].

Many species of macroalgae are known to have high levels of carbohydrate, although in many cases these carbohydrates consist of galactose [54]. Recent research has shown that the red algae Gelidium amansii and the brown algae Laminaria japonica are both a potential biomass source for biohydrogen production through anaerobic fermentation $[54,55]$. Recently, microalgae have also been paid attention from the point of view of biogas production in the anaerobic fermentation [4].

\section{Metabolism of photosynthetic microorganisms}

Oxygenic photosynthesis is the process by which plants, algae, and cyanobacteria convert sunlight and $\mathrm{CO}_{2}$ into chemical energy and biomass. The algal photosynthesis is at least able to convert approximately $5 \%$ to $7 \%$ of incident light energy to biomass, where a systems-based approach to understand the stresses and efficiencies associated with light energy harvesting, $\mathrm{CO}_{2}$ fixation, and carbon partitioning is necessary to make headway toward improving photosynthetic yields [56].

The cell growth conditions are roughly classified as autotrophic condition for the case of using only $\mathrm{CO}_{2}$ under light condition, mixotrohphic condition for the case of using both carbohydrate and $\mathrm{CO}_{2}$ under light condition, and heterotrphic condition for the case of using carbohydrate under dark condition. Although autotrophic condition is preferred from the environmental protection point of view using only $\mathrm{CO}_{2}$ as a carbon source, the cell growth rate is significantly low, and thus the productivity of the metabolic products is low.

The atmospheric $\mathrm{CO}_{2}$ is fixed either by $\mathrm{C}_{3}$ photosynthesis where the three carbon molecule such as 3phosphogrycerate (3PG) is used as the product of ribulose 1,5-bisphosphate carboxylase (RubisCO) reaction or by $\mathrm{C}_{4}$ photosynthesis where four carbon molecule such as oxaloacetate (OAA) is used as the product of phosphoenol pyruvate (PEP) carboxylase (Ppc) reaction followed by the decarboxylation at malic enzyme (Mez) from malate yielding pyruvate. The $\mathrm{C}_{4}$ photosynthesis may be created by evolution from ancestral $\mathrm{C}_{3}$ photosynthesis during a global decline in atmospheric $\mathrm{CO}_{2}$ level [57]. The $\mathrm{C}_{4}$ pathway will have higher efficiency than the $\mathrm{C}_{3}$ pathway in $\mathrm{CO}_{2}$ fixing with which they consume water and nitrogen [58].

Since $\mathrm{CO}_{2}$ fixation is attractive from the environmental protection point of view, several strategies have been considered for the efficient carbon fixation for the cell 
synthesis [59], where carbon fixation can be enhanced by amplifying carboxysome expression [60] or heterologous expression of RubisCO gene $r b c L S$ [61]. The $\mathrm{CO}_{2}$ fixation can be also enhanced by a hybrid RubisCO, which contains both plant and microalgae subunits [62].

The green organisms such as plants and algae gain energy via aerobic respiration, and the metabolism changes depending on the oxygen availability. The green organisms are exposed to a variety of oxygen availability in the environment that may vary from fully aerobic state (normoxia) to oxygen deficiency (hypoxia) or the anaerobic condition (anoxia). In the context of recent climate change, excess rainfall and frequent flooding may cause the green cells subjected to hypoxia or anoxia condition [63]. Oxygen is the final acceptor of electrons in the mitochondrial oxidative phosphorylation to generate ATP, while under hypoxia and anoxia conditions, the small amount of ATP is generated through glycolysis, and $\mathrm{NAD}(\mathrm{P}) \mathrm{H}$ must be reoxidized by the fermentative pathways. Under oxygen-limiting condition, the glycolysis flux is accelerated by the so-called 'Pasteur effect', and plant metabolism uses pyruvate to direct towards ethanolic and lactic fermentations [64]. In almost all plant, a rapid activation of lactate dehydrogenase (LDH) has been observed under oxygen limitation [63]. Lactate production causes damage to the cell by lowering cytoplasmic $\mathrm{pH}$, and thus lactate production is transient eventually replaced by ethanolic fermentation. The $\alpha$ ketoglutaric acid $(\alpha K G)$ in the TCA cycle can be oxidized with the incorporation of $\mathrm{NH}_{4}^{+}$and NADH to form glutamate (Glu), which is then decarboxylated to $r$-amino butyric acid (GABA) by glutamate decarboxylase (GDC), where some protons are utilized in GDC reaction and stabilizes the cytosolic $\mathrm{pH}$ [63].

\section{Metabolism of algae}

It is critical to properly understand the metabolism in response to culture environment, where the systems biology approaches including metabolite profiling [65] and integration of different levels of information such as metabolites, fluxes, transcript, and protein abundance [66] are useful.

Consider the metabolism of photosynthetic microorganisms [67]. The light energy is incorporated into the cell, where light quanta absorbed by pigments drive the photosynthetic electron transport, where NADPH instead of NADH is used to generate ATP at the respiratory chain. The primal pathway for $\mathrm{CO}_{2}$ fixation is the Calvin-Benson-Bassham (CBB) cycle, where the first step is catalyzed by RubisCO (Figure 1). This enzyme is also an oxygenase, which can react with $\mathrm{O}_{2}$ and lead to a different pathway called photorespiration. Algae have the photorespiration pathway, and photosynthesis is inhibited by high $\mathrm{O}_{2}$ concentration. Photosynthesis reactions such as light reactions, $\mathrm{CBB}$ cycle, and starch synthesis occur in chloroplasts. Algae and plant cells have subcellular compartments such as chloroplast, mitochondria, and cytoplasm. After the export of GAP from the chloroplast to cytoplasm, the carbon flow is divided into the sugar synthesis pathway or the glycolytic pathway to form pyruvate. Sugars such as sucrose are the major storage products in the cytoplasm of plant cells. In plant cells, replenishment of carbon to maintain the operation of the TCA cycle is achieved by anaplerotic reactions involving $\mathrm{CO}_{2}$ fixation by PEP carboxylase (Ppc). The pentose phosphate $(\mathrm{PP})$ pathway operates in the cytoplasm, where $\mathrm{CBB}$ cycle is functioning in the chloroplast.

Of all the pigments, chlorophyll takes a major fraction. $\delta$-aminolevulinic acid ( $\delta$-ALA) is the key chlorophyll precursor molecule. The classical succinate-glycine pathway is the condensation of glycine and succinyl-CoA catalyzed by $\delta$-ALA synthetase. In addition, glutamate and $\alpha K G$ are incorporated into $\delta$-ALA much more efficiently than are glycine and succinate in many green cells. Although most of the fatty acid synthesis occurs in the chloroplast, the source of acetyl-coenzyme. A (AcCoA) derives from its synthesis in the mitochondria. The fatty acid composition of the lipids of Chlorella cells varies considerably, particularly for the $\alpha$-linolenic acid (C18:3) content [67].

Under autotrophic condition, significant ATP is formed from mitochondrial oxidative phosphorylation. The CBB cycle is the main ATP sink in the autotrophic culture. The ATP yield decreases in the following order: heterotroph > mixotroph > autotroph [67].

\section{Metabolism of cyanobacteria}

Cyanobacteria are commonly used as model systems for the metabolism of higher plants. Cyanobacteria possess certain promising properties such as (1) large amounts of lipids, commonly present in thylakoid membranes, (2) higher photosynthetic levels and the cell growth rates compared to algae and higher plants, (3) easy growth with basic nutritional requirements such as air $\left(\mathrm{CO}_{2}+\mathrm{N}_{2}\right)$, water, and mineral salts with light [68].

The central metabolic network in Synechocystis is shown in Figure 2, which includes those of the glycolysis, PP pathway, CBB cycle, part of TCA cycle, and the C1 metabolism. Cyanobacteria have an incomplete TCA cycle lacking aketoglutarate dehydrogenase (KGDH) [69,70]. The enzymes, isocitrate lyase (Icl) and malate synthase (MS), which form the glyoxylate pathway, function in cyanobacteria [71]. The Mez and PEP synthase (Pps) are responsible for the gluconeogenetic steps, where the PEP carboxy kinase (Pck) is absent in Synechocystis. The PP pathway operates for glucose catabolism mainly in the heterotrophic conditions, while the $\mathrm{CBB}$ cycle is active under mixotrophic and autotrophic conditions. 


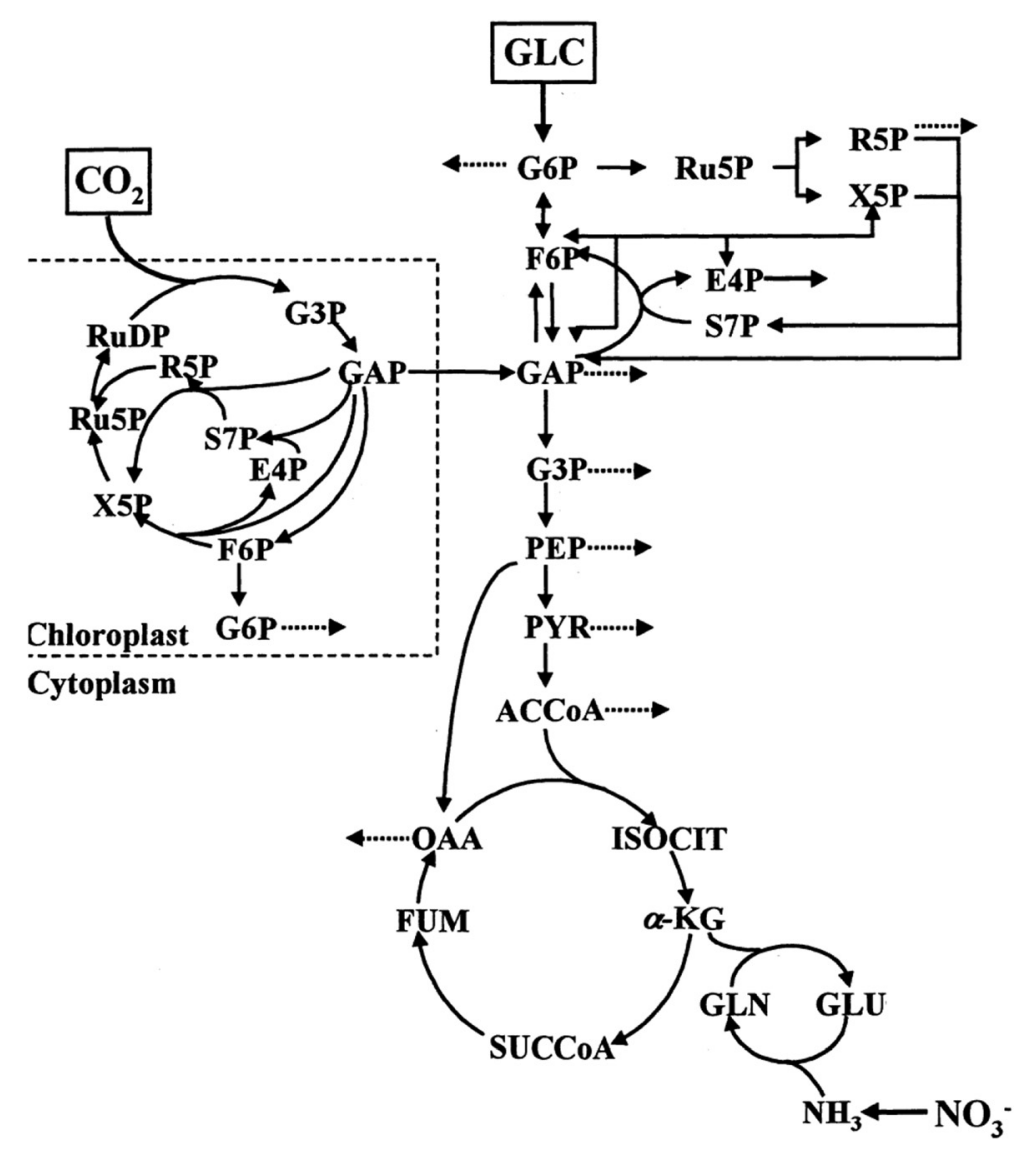

Figure 1 Metabolic pathways of photosynthetic microorganism (adapted from [67]).

The metabolic flux analysis of Synechocystis cultivated under heterotrophic and mixotrophic conditions has been made based on ${ }^{13} \mathrm{C}$-metabolic flux analysis $\left({ }^{13} \mathrm{C}\right.$-MFA) [72,73], and the metabolic regulation analysis has also been made with integration of different levels of information [74]. In the heterotrophic cultivation of Synechocystis, more than $90 \%$ of glucose is channeled through the PP pathway (Figure 3) [72,73]. The high flux through the oxidative PP pathway yields a large amount of NADPH, as well as biosynthetic precursors such as ribose 5-phospate (R5P) and erythrose 4-phosphate (E4P). In the mixotrophic culture, $\mathrm{CO}_{2}$ is fixed through the $\mathrm{CBB}$ cycle. The conventional ${ }^{13} \mathrm{C}$-MFA is based on the steady state and thus limited to heterotrophic and mixotrophic conditions $[72,73,75]$, while ${ }^{13} \mathrm{C}$-MFA for autotrophic condition can be made by the isotopically nonstationary metabolic flux analysis (MFA) [76] with transient measurements of isotope incorporation following a step change from unlabeled to labeled $\mathrm{CO}_{2}$ (Figure 3) [77].

Since cyanobacteria have negligible photorespiration and produce little or no glycolate during photosynthesis, it is unlikely that serine is synthesized, as in higher plants, from glycine by the glycolate pathway. Serine is synthesized directly from 3PG through a phosphorylated route in cyanobacteria [78].

Under both heterotrophic and mixotrophic conditions, the relative flux through $\mathrm{Ppc}$ is high. The reaction catalyzed by Ppc contributes to about $25 \%$ of the assimilated $\mathrm{CO}_{2}$ under mixotrophic condition [72,73], indicating that Ppc is important for the fixation of $\mathrm{CO}_{2}$ in cyanobacterial cells [79], where cyanobacterial cells fix significant amounts of carbon as $\mathrm{C} 4$ acids under light conditions. Considering that Mez in cyanobacteria is NADP-linked [80], it is more likely that Ppc and Mez serve as a device to fix a large amount of $\mathrm{CO}_{2}$ as $\mathrm{C} 4$ acids and then release $\mathrm{CO}_{2}$ and produce NADPH by the decarboxylation of malate. This Ppc and Mez pathways can effectively bypass the Pyk reaction, where its activity is repressed under light condition [77]. This is similar to the carbon metabolism in $\mathrm{C} 4$ plants, for which $\mathrm{CO}_{2}$ and $\mathrm{NADPH}$ generated by Mez are utilized by the $\mathrm{CBB}$ cycle. In fact, although the major pathway of $\mathrm{CO}_{2}$ fixation in the $\mathrm{CBB}$ cycle is similar to that in $\mathrm{C} 3$ plants, cyanobacteria have many of the physiological characteristics of $\mathrm{C} 4$ plants.

In the mixotrophic culture, copious amounts of reducing power are required in the $\mathrm{CBB}$ cycle to fix $\mathrm{CO}_{2}$ to 


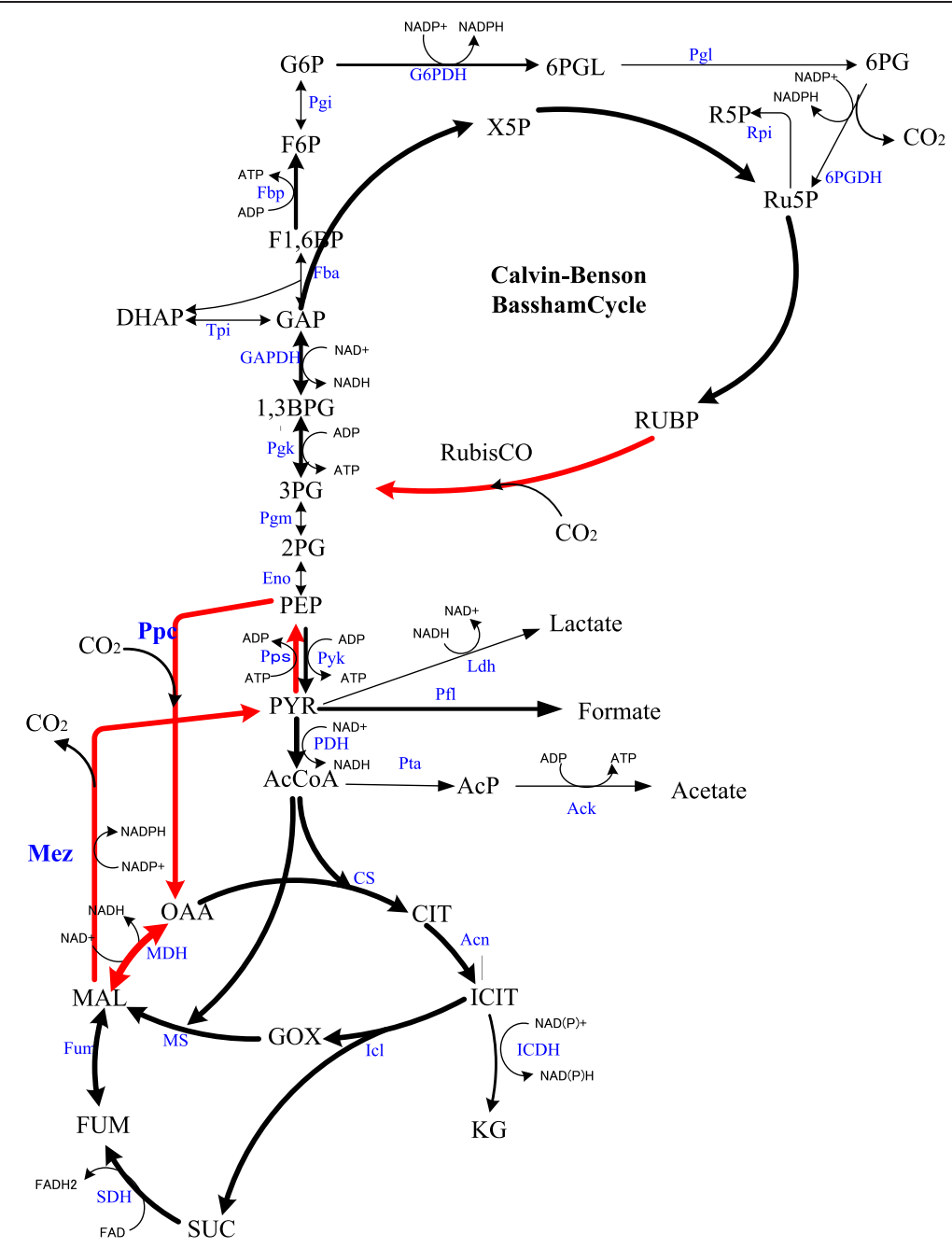

Figure 2 Metabolic pathways of cyanobacteria.

carbohydrates. Hence, there has to be a supply of NADPH in large amounts to fulfill the biosynthetic demands. The PP pathway in the heterotrophic culture and the photosynthetic electron transport in the mixotrophic culture accounts for a major fraction of NADPH production. Moreover, cyanobacteria utilize NADPH as an electron donor of the respiratory electron transport chain. Therefore, the excess NADPH is reoxidized during respiration to provide energy. The CBB cycle is the main ATP sink in the mixotrophic culture.

\section{Catabolic regulation and carbon storage regulation under nitrogen limitation}

Like many bacteria on earth, photosynthetic organisms are found in diverse ecological habitats, where the organisms are exposed to periods of severe nutrient starvation. In particular, cyanobacteria are found in a wide range of ecological habitats including oceans and lakes [81]. They also survive in deserts, polar regions, and hot springs, where the nutrient starvation is much more severe.

Under unfavorable growth condition such as nitrogen starvation, TAG is typically produced in microalgae, where its fraction ranges from $20 \%$ to $60 \%$ (weight/dry weight) [82]. The efficient production of TAG in microalgae requires a thorough understanding of lipid metabolism and TAG accumulation [83]. It is important to analyze different levels of information to uncover the molecular mechanism underlying the increased TAG accumulation for microalgae such as $C$. reinhardtii and its starchless and cell wall-deficient mutant strains [84].

Cyanobacteria have sophisticated mechanisms to cope with nitrogen limitation, where the primary step is the capture of nitrogen-containing compounds with high affinity, where nitrate, nitrite, and ammonium are the typical nitrogen sources with a preference for ammonium [85]. Some strains can fix dinitrogen gas and may use also urea, cyanate, and amino acids as additional nitrogen 


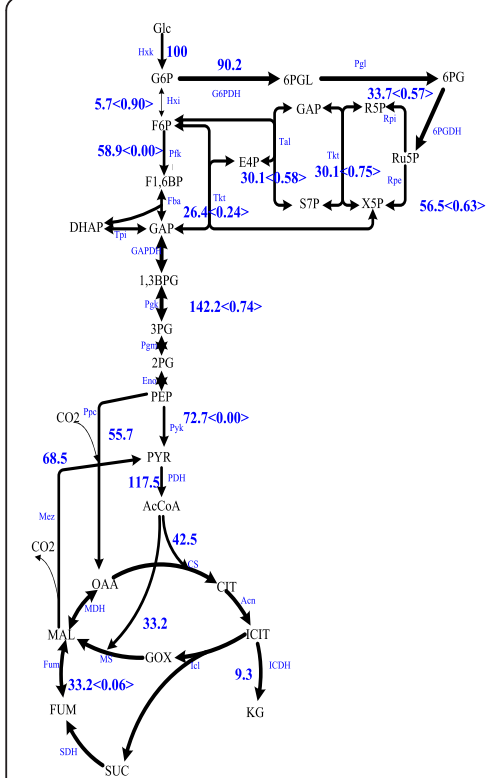

(a)

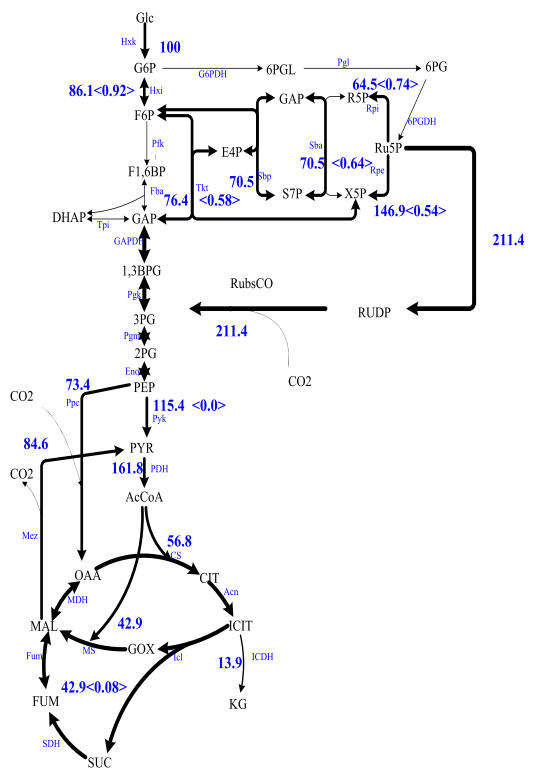

(b)

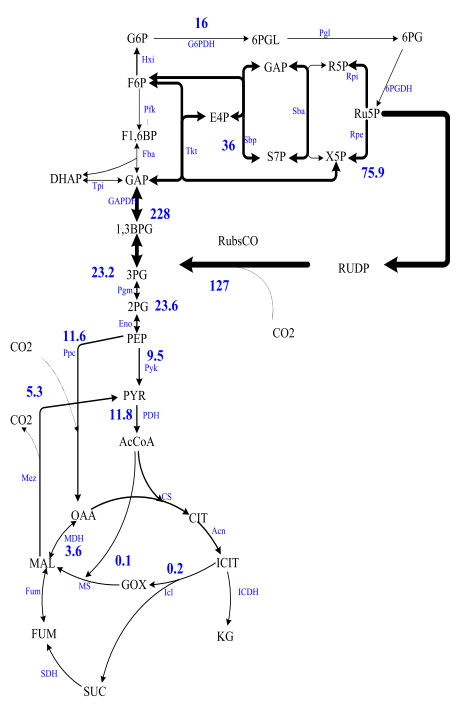

(c)

Figure $3{ }^{13}$ C-Metabolic flux distribution of Synecocystis sp. PCC6803 cultivated under heterotrophic (a), mixotrophic (b), and (c) autotrophic conditions. The flux values were obtained from [73] for (a) and (b) and from [77] for (c).

sources [85-87]. Nitrogen compounds are eventually converted to ammonium and assimilated for biosynthesis via the glutamin synthetase (GS)-glutamine oxoglutarate aminotransferase or glutamate synthase (GOGAT) cycle, where glutamate dehydrogenase (GDH) pathway does not function, probably due to low affinity to ammonium.

For survival under nitrogen starvation, cyanobacteria accumulate reserve materials in the form of inclusions and granurs, where the induction for their accumulation is made upon high light or $\mathrm{CO}_{2}$, nutrient starvation as well as addition of arginine or chloramphenicol [88]. Cyanophycin (multi-l-arginyl-poly-[L-aspartic acid]) is a nitrogen reserve and is a non-ribosomally synthesized peptide consisting of equi-molar quantities of alginine (Alg) and aspatic acid (Asp), where cyanobacteria may consume internal storage compounds such as cyanophycin as nitrogen source upon nitrogen starvation $[88,89]$.

After cyanophycin is exhausted, cells degrade the phycobilisomes that are large protein-rich right-harvesting antennae attached to the outside of the thylakoid membranes and support the light-dependent reactions of photosynthesis [90], where it is composed of rod and core proteins to provide nitrogen, which leads to a color change of cells from blue-green to yellow-green, known as bleaching [90]. Upon availability of nitrogen source again, cyanophycin is immediately synthesized [89].

Nutrient balance is important for the cell growth, since proteins, nucleic acids, carbohydrates, lipids, and pigments must be supplied in a suitable ratio for the balanced growth. In eukaryotic microalgae, autophagy is induced by nitrogen starvation to degrade cytoplasmic components including plastids in the large vacuoles [91]. In cyanobacteria, a unique $\mathrm{Nb} 1 \mathrm{~A}$-dependent mechanism is induced to degrade certain phycobiliproteins, where the non-bleaching phenotype gene, $n b l A$ plays an important role for the degradation of phycobiliprotein $[92,93]$. The phycobilisome has a role in nitrogen storage as well as photosynthetic antenna [90]. Moreover, NblA1/A2-dependent protein turnover contributes to the maintenance of many amino acids (AAs) in NblA1/A2-dependently, while Lys pool markedly increased under sulfur starvation in cyanobacteria [94].

The internal $\mathrm{C} / \mathrm{N}$ ratio is sensed by the PII protein, $\mathrm{G} \operatorname{lnB}$, in particular under N-limitation [95]. The global nitrogen regulator NtcA plays important roles for nitrogen regulation, where it senses $\alpha K G$ levels and regulates the genes involved in nitrogen assimilation. NtcA directly regulates the expression of $n r r A$ gene which encodes a nitrogen-regulated response regulator of the OmpR family. NrrA is involved in induction of sugar catabolic genes as well under nitrogen starvation [96]. NrrA also regulates glycogen catabolism in Anabaena sp. by directly regulating expression of $g l g P$ gene encoding glycogen phosphlylase and sigE gene encoding a group $2 \sigma$ factor of RNA polymerase [97]. Nrr controls cyanophycin accumulation and glycogen catabolism in cyanobacteria [98], where glycogen is accumulated, whereas the expression of sugar catabolic genes is widely upregulated under nitrogen starvation [99]. 
Microalgae produce certain biomass compounds under nutrient limitation [100]. In cyanobacteria such as Synechocystis sp., polyhydoxy butyric acid (PHB), one of polyhydroxy alcanoate (PHA), is accumulated under nitrogen or phosphate starvation, where $\mathrm{PHB}$ is formed from AcCoA via $\beta$-keto-thiolase (PhaA), acetoacetyl-CoA reductase $(\mathrm{PhaB})$, and PHA synthase $(\mathrm{PhaC})$, where PHA synthase is activated by acetyl phosphate (AcP) [101]. Since acetoacetyl-CoA reductase requires $\mathrm{NADPH}$, the pathway modification that causes excess NADPH yields higher PHB production [102].

Cyanobacteria have nine sigma factors such as SigA-I, where RNA polymerase sigma factor SigE plays important roles under nitrogen starvation [103]. SigE activates the expression of the genes associated with degradation of glycogen and catabolic genes of glycolysis and PP pathway [104]. Moreover, SigE activates PHB synthetic pathway gene expression [105], and thus the overexpression of sigE allows higher PHB production under nitrogen limitation [106]. Moreover, SigE also activates the expression of hydrogenase gene, and thus the overexpression of sigE also allows higher hydrogen production under anaerobic condition [107].

Cyanobacteria have two types of sunscreen pigments such as scytonemin and mycosporine-like amino acids, where these secondary metabolites play roles against environmental stresses such as UV radiation and desiccation [108].

Systems biology approach and modeling of the metabolism Although algae and cyanobacteria have been paid recent attention for the potential to the sustainable biosynthesis, unknown and uncharacterized gene and protein functions hamper the progress toward the future era of algae industrial biotechnology. The systems biology approach plays a crucial role for function prediction based on the database with proper metabolic modeling [109].

Some attempts have been made for the modeling of photosynthetic organisms [110,111], while mechanistic model of photosynthesis in microalgae has also been developed [112,113]. The sequential statistical analysis based on experimental design coupled with least squares multiple regression has been made to analyze the dependence of respiratory and photosynthetic responses upon concomitant modulation of light intensity as well as acetate, $\mathrm{CO}_{2}$, nitrate, and ammonia concentrations in the culture of $C$. reinhardtii [114].

MFA may be considered to gain insight into the metabolism, where the optimal light intensity can be identified for the biomass yield of $C$. reinhardtii by considering the cell maintenance and biomass formation [115]. A mixed integer linear programming method was used to find the optimal flux distributions of $C$. reinhardtii cultivated under photoautotrophic conditions in photobioreactors functioning in physical light limitation based on the constraint-based model, which includes thermodynamic and energetic constraints on the functioning metabolism, highlighting the existence of a light-driven respiration depending on the incident photon flux density [116].

Flux balance analysis (FBA) based on the network consisting of 484 metabolic reactions and 458 intracellular metabolites for $C$. reinhardtii indicates that aerobic heterotrophic growth on acetate has a low yield on carbon, while mixotrophically and autotrophically grown cells are significantly more carbon efficient [117]. A genomescale extension for $C$. reinhardtii has been made with the network consisting of 1,080 genes, associated with 2,190 reactions and 1,068 metabolites (named $i \mathrm{RC} 1080$ ), that enables quantitative growth prediction for a given light source, resolving wavelength and photon flux. This offers insight into algae metabolism and potential for genetic engineering and efficient light source design [118]. Another comprehensive literature-based genome-scale model with the network of 866 ORFs, 1,862 metabolites, 2,249 gene-enzyme-reaction-association entries, and 1,725 reactions has been developed (named AlgaGEM), where it predicted observable metabolic effects under autotrophic, heterotrophic, and mixotrophic conditions, and predicts increased hydrogen production when cyclic electron flow is disrupted, and the physiological pathway for $\mathrm{H}_{2}$ production, which identified new targets for further improvement of $\mathrm{H}_{2}$ yield [119].

FBA approach has also been employed for cyanobacteria with the emphasis on the alleged glyoxylate shunt and the role of photorespiration in cellular growth and analyzed the diurnal light/dark cycles of the metabolism [120]. Genome-scale metabolic model of Synechococcus elongates PCC7942 (named iSyf715) has also been developed with the network of 851 reactions and 838 metabolites, and the applicability has been demonstrated for autotrophic growth conditions [121].

\section{Metabolic modification for various biofuel and biochemical production}

Algae have the potential for the genetic modification of their lipid pathways by upregulation of fatty acid biosynthesis or by downregulation of $\beta$-oxidation. By knocking out or modifying enzymes responsible for the synthesis of polyunsaturated lipids in the cell, it may be possible to dramatically increase the production of mono-unsaturated lipids [122]. Under optimal growth condition, the wildtype Chlamydomonas strains accumulate very low amount of oil $\left(<1 \mu \mathrm{g}\right.$ per $10^{6}$ cells) [45]. When cells are subjected to nitrogen starvation, oil content can be increased more than tenfold (up to $10 \mu \mathrm{g}$ per $10^{6}$ cells) [43-45]. Intracellular TAG amounts also fluctuate during the diurnal cycle because TAGs produced during the day provide a carbon and energy source for the night [123]. This is the major 
factor to yield loss in open pond microalgae cultivation. Researchers have not been able to achieve efficient homologous recombination in the nuclear genome of the commonly transformed laboratory algal strain $C$. reinhardtii, but this is not the case for the marine alga and biofuel candidate Nannochloropsis [124].

As a result of genetic engineering, some obligate photoautotrophs, formerly unable to partake in a sweet diet, have been given a taste of heterotrophy through the introduction of hexose transporters [125]. In the starchless mutant of Chlamydomonas, the flux through starch production redirects to lipid accumulation under nitrogen-starved condition. The strain should be designed to switch off completely for starch accumulation under nitrogen-starved condition. Blocking oil turnover processes might help increase the level of oil accumulated, as was observed in Arabidopsis leaves where the oil content was increased tenfold by knocking out a lipase gene [126].

Most metabolic engineering investigations have been made using such typical model organisms as Synechocystis sp. and Synechococcus elongatus sp. as well as Aanabaena sp., whereas much more complex genetic engineering is required for algae [16].

Bioethanol can be produced by introducing pyruvate decarboxylase (PDC) and alcohol dehydrogenase (ADH) genes from $Z$. mobilis into the shuttle vector and then transform Synechosystis sp. [127,128] (Table 1).

As shown in Figure 4, 2-ketoisovalerate can be converted to isobutyraldehyde by introducing ketoacid decarboxylase gene kivd from Lactococcus lactis into the genome of S. elongatus PCC7942 [61]. The flux to 2ketoisovalerate can be improved by introducing alsS gene from Bacillus subtilis and the $i l v C$ and $i l v D$ genes from $E$. coli into the chromosome of $S$. elongatus. Carbon fixation can be improved by overexpression of RubisCO genes to increase the productivity of isobutyraldehyde. Iso-butanol can then be produced by introducing alcohol dehydrogenase YqhD from Escherichia coli [61].

2-Methyl-1-butanol (2 MB) can be produced in $S$. elongatus by expressing heterologous enzymes for citramalate pathway [129] to direct pyruvate toward isoleucine sysnthesis pathway, where 2-keto-3-methyvalerate is converted to $2 \mathrm{MB}$ by Kivd and YqhD [130] (Table 1).

1-Butanol can be produced from AcCoA by anaerobic dark condition by engineered $S$. elongatus by introducing acetyl transferase (AtoB) from E. coli, 3-hydroxybutyrylCoA dehydrogenase (Hbd) from Clostridium acetobutylicum, trans-2-enoyl-CoA reductase (Ter) from Treponema denticola, crotonase (Crt) from $C$. acetobutylicum, and bifunctional aldehyde/alcohol dehydrogenase (AdhE2) from C. acetobutylicum [131]. 1-Butanol can be also produced by aerobic culture of S. elongates PCC7942, where condensation of AcCoA is made by consuming ATP with $\mathrm{CO}_{2}$ evolution [132], where ATP-dependent malonyl-CoA synthesis enzyme NphT7 was introduced, and NADHdependent enzymes were replaced by NADPH-dependent enzymes in this strain. Butanol tolerance of Synechocystis can be improved by $150 \%$ by evolution by gradually increasing butanol concentration from $0.2 \%$ to $0.5 \%(v / v)$ [133] (Table 1).

Lactic acid has been used in the food and pharmaceutical industries and for biodegradable polymers [134], and this can be produced in Synechosystis after heterologous expression of LDH $[135,136]$. Since Pyk is inhibited under light condition in Synechosystis, heterologous expression of Pyk can enhance the pyruvate production and in turn enhance the lactate production, where Pyk is allosterically activated by fructose 1,6-bisphosphate (FBP) in the case of Pyk-F originated form E. coli, while the original Pyk does not show such characteristics [136]. Moreover, Ppc may be knocked down to direct the carbon flow from PEP towards lactate production via PYR, but the cell growth is depressed, since Ppc is also an important pathway for $\mathrm{CO}_{2}$ fixation [136]. In most bacteria, LDH requires cofactor $\mathrm{NADH}$, whereas NADPH is abundant in Synechosystis as mentioned before, and thus NADPH-dependent LDH may increase the lactate production, where this may be partly attained by introducing the LDH from B. subtilis, of which LDH co-utilizes NADH and NADPH [136,137] (Table 1).

Isoprene is a volatile compound and utilized in the synthesis of rubber etc., where isoprene is easily evaporated from the culture broth, and thus the toxicity to the cell can be relaxed by evaporation, where it can be trapped in the gas phase. Isoprene can be synthesized by Synechocystis sp. PCC6803 by introducing lspS gene from vine Pueraria montana and utilizing the naturally occurring methyl-erythritol-4-phosphate (MEP) pathway (Figure 4) [138] (Table 1).

Ethylene is another volatile compound, where this can be also produced by Synechocystis sp. PCC6803 by introducing ethylene forming pathway gene efe from Pseudomonas syringae pv phaseolicola (Figure 4) [139] (Table 1).

Fatty acid and fatty alcohol production can be made by Synechocystis sp. PCC6803 by overexpression of endogenous fatty acyl-ACP synthase gene slr1609 (Figure 4) [140]. Only fatty acids can be produced and excreted outside of the cell by modification of Synechocystis sp. PCC6803 [141,142]. Fatty alcohols such as hexadecanol and octadecanol can be produced by introducing fatty acyl-CoA reductase genes from jojoba, which catalyze a fatty-acyl-ACP (Figure 4) [143] (Table 1).

Eucaryotic algae have also been considered for fatty acid production, where they can accumulate lipids up to about $70 \%$ of dry biomass [41,144]. The limitations of using algae are the complexity of the eukaryotic system and less available genetic tools, although some attempts have been done [145]. Some efforts are being made to 
Table 1 Biofuel and biochemical production by cyanobacteria

\begin{tabular}{|c|c|c|c|c|c|}
\hline Product & Species & Titer or productivity & Overexpressed or knockout gene (s) & Cultivation & Reference \\
\hline \multirow[t]{3}{*}{ Ethanol } & Synechococcus & $230 \mathrm{mg} / \mathrm{L}$ in 28 days & $p d c, a d h$ & Shake flask & [210] \\
\hline & Synechocystis & $552 \mathrm{mg} / \mathrm{L}$ in 6 days & $p d c, a d h$ & Photobioreactor & [127] \\
\hline & Synechocystis & $608 \mathrm{mg} / \mathrm{L}$ in 18 days & $p d c, a d h$ & Photobioreactor & [128] \\
\hline Isobutyraldehyde & Synechococcus & $1,100 \mathrm{mg} / \mathrm{L}$ in 8 days & alsS, ilvC,D, kivd, rbcls & Bottle with $\mathrm{NaHCO} 3$ & [61] \\
\hline \multirow[t]{2}{*}{ Isobutanol } & Synechococcus & $18 \mathrm{mg} / \mathrm{L}$ & kivd, yqhD & Shake flask with $\mathrm{NaHCO} 3$ & {$[61]$} \\
\hline & synechococcus & $450 \mathrm{mg} / \mathrm{L}$ in 6 days & alsS, ilvC, D, kivd, yqhD & Shake flask with $\mathrm{NaHCO} 3$ & [61] \\
\hline 2 Methyl-1-butanol & Synechococcus & $2 \mathrm{mg} / \mathrm{L}$ & kivd, yqhD, cims & Shake flask with $\mathrm{NaHCO} 3$ & {$[61,130]$} \\
\hline \multirow[t]{2}{*}{ 1-Butanol } & Synechococcus & $14.5 \mathrm{mg} / \mathrm{L}$ in 7 days & $h b d, c r t, a d h E 2$, ter, atoB & Bottle under anoxic cond. & [131] \\
\hline & Synechococcus & $30 \mathrm{mg} / \mathrm{L}$ in 18 days & ter, nphT7, bldh, yqhD, phaJ, B & Shake flask & [132] \\
\hline \multirow[t]{3}{*}{ Fatty alcohol } & Synechocystis & $0.2 \mathrm{mg} / \mathrm{L}$ in 18 days & far & $\begin{array}{l}\text { Photobaioreactor with } 5 \% \\
\mathrm{CO}_{2}\end{array}$ & [143] \\
\hline & Synechocystis & $0.02 \mathrm{mg} / \mathrm{L} / \mathrm{OD}$ & far,aas & Shake flask & [140] \\
\hline & Synechocystis & $2.87 \mathrm{mg} / \mathrm{gDCW}$ & $\Delta s / 10208, \Delta s / 10209$ & Flask & [211] \\
\hline Fatty acids & Synechocystis & $197 \mathrm{mg} / \mathrm{L}$ in 17 days & tes $A$, accBCDA, fatB1, B2, tes $A 137$ & $1 \% \mathrm{CO}_{2}$ bubbling & [142] \\
\hline \multirow[t]{2}{*}{ Alka (e) nes } & Synechocystis & $0.162 \mathrm{mg} / \mathrm{L} / \mathrm{OD}$ & $\operatorname{accBCDA}$ & Shake flask & [143] \\
\hline & Synechocystis & $2.3 \mathrm{mg} / \mathrm{l} / \mathrm{OD}$ & sll0208, sll0209 & Shake flask & [212] \\
\hline \multirow[t]{2}{*}{ Hydrogen } & Synechococcus & $2.8 \mu \mathrm{mol} / \mathrm{h} / \mathrm{mgChlorophyll-a}$ & hydEF, hydG, hydA & Anaerobic condition & [153] \\
\hline & Synechococcus & $\begin{array}{c}54 \mathrm{mmol} / 1,017 \text { cells in } \\
4 \text { days }\end{array}$ & $\Delta / d h$ & Anoxic condition & [213] \\
\hline \multirow[t]{2}{*}{ L-Lactate } & Synechocystis & $0.0178 \mathrm{mmol} / \mathrm{gDCW} / \mathrm{h}$ & ldh, sth & Shaking incubator & [214] \\
\hline & Synechocystis & $0.2512 \mathrm{mmol} / \mathrm{gDCW} / \mathrm{h}$ & pyk, ldh & Shaking incubator & [136] \\
\hline D-Lactate & Synechocystis & $2.17 \mathrm{~g} / \mathrm{L}$ in 24 days & gldA, sth & Photoautotropic with acetate & [215] \\
\hline 1,2-propanediol & Synechococcus & Approximately 150 mg/L & $m g s A$, gldA, yqhD & Shake flask & [216] \\
\hline Isoprene & Synechocystis & $50 \mu \mathrm{g} / \mathrm{gDCW} / \mathrm{d}$ & IspS & Sealed culture & [138] \\
\hline \multirow[t]{4}{*}{ Ethylene } & Synechocystis & $26 \mu \mathrm{mol} / \mathrm{gDCW} / \mathrm{h}$ & efe (RS1010) & Rotary shaker & {$[217]$} \\
\hline & Synechocystis & $111.6 \mu \mathrm{mol} / \mathrm{gDCW} / \mathrm{h}$ & efe (str068) & Rotary shaker & {$[217]$} \\
\hline & Synechococcus & $84.8 \mu \mathrm{mol} / \mathrm{gDCW} / \mathrm{h}$ & efe (pUC303) & Flask & [218] \\
\hline & Synechococcus & $80.5 \mu \mathrm{mol} / \mathrm{gDCW} / \mathrm{h}$ & efe (psbAl) & Flask & [219] \\
\hline Acetone & Synechocystis & $36.0 \mathrm{mg} / \mathrm{L}$ in 4 days & ctfAB, adc, $\Delta p h a C E, \Delta p t a$ & Flask & [148] \\
\hline \multirow[t]{2}{*}{ PHAs } & Synechocystis & $1.4 \mathrm{mg} / 100 \mathrm{mgDCW}$ & sigE & $\begin{array}{l}\text { Bubbled with } 1 \% \mathrm{CO}_{2} \text { in the } \\
\text { air }\end{array}$ & [106] \\
\hline & Synechocystis & $533.4 \mathrm{mg} / \mathrm{L}$ in 21 days & $\Delta s \operatorname{lr} 1829, \Delta s \operatorname{sr} 1830$ & Flask & {$[220]$} \\
\hline
\end{tabular}

identify stress conditions and key enzymes for fatty acid synthesis in the green algae Haematococcus pluvialis [146]. Effects of light conditions on fatty acid production were also investigated for Nannochloropsis [147].

Acetone can be used as the precursor for isopropanol. This can be produced in Synechocystis PCC6803 by introducing $\mathrm{CoA}$ transferase (CtfAB) and acetoacetate decarboxylase (Adc) from $C$. acetobutylicum for converting AcCoA to acetone (Figure 4) [148], where the PHBforming pathway genes phaCE and the acetate-forming pathway gene $p t a$ may be disrupted. Alpha-olefin production can be also made by Synechococcus sp. PCC7008 [149] (Table 1).
Methane can be produced by co-culture of $C$. reinhardtii and methanogenic bacteria, where glyconate is produced from the former, while methane is produced from the latter by assimilating glyconate [150]. Rhodobacter are non-sulfur photosynthetic bacteria that produce hydrogen $\left(\mathrm{H}_{2}\right)$ from acetate etc. Hydrogen production may be enhanced by introducing aldehyde dehydrogenase (ALDH) gene from Rhodospirillum rubrum into Rhodobacter sphaeroides [151]. Hydrogen production can be enhanced by introducing exogenous hydrogenase into nitrogen fixing [152] and non-nitrogen fixing cyanobacteria [153]. Hydrogen production can be improved by introducing hydrogenase from Clostridium thermocellum into Rhodopseudomonas 


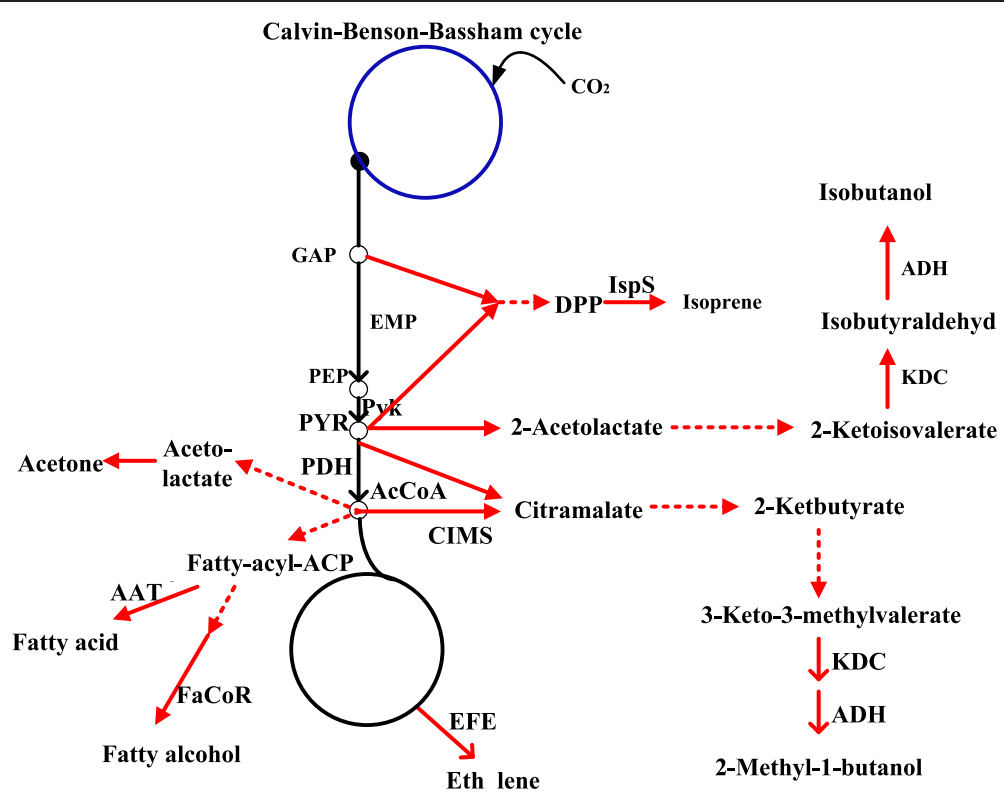

Figure 4 A variety of metabolic pathways for the production of biofuels and biochemicals.

palustris CGA009 and cultivated at $38^{\circ} \mathrm{C}$ by considering the outdoor bioreactors [152]. Hydrogen can be produced by introducing a hydrogenase HydA from $C$. acetobutylicum into S. elongates [153], and its production can be significantly improved in Arthosporia by continuously removing it from the culture broth [154].

Another important aspect of utilizing photosynthetic organisms is their ability of producing pharmaceuticals due to the reduction of ketones [155-157]. Microalgae are also attractive for their production of antioxidants, where Fischerella ambigua and Chlorella vulgaris show higher antioxidant activities [158]. Phenolic compounds have also antioxidant properties, where their production can be enhanced in Spirulina platensis by manipulating light intensities [159].

Phycocyanin is also attractive, where its production by Arthospira (Spirulina) platensis was investigated in marine environment [160]. The pigment sesquiterpene $\beta$-caryophyllene can be produced by Synechocystis sp. PCC6803 with the aid of a $\beta$-caryophyllene synthase gene from Artemisia annua [161], where this compound is used in the fragrance and cosmetic industry, and in natural remedies for its anti-inflammatory and antimicrobial properties. Lycopene is also important food additives and pigment, and can be produced by a purple non-sulfur bacterium, $R$. rubrum, by deletion of downstream phytoene desaturase gene $\operatorname{crt} C$ and $\operatorname{crtD}$ [162].

Cyanobacteria can excrete fructose, lactate, and glucose by introducing transport genes from E .coli [134]. Many cyanobacteria naturally produce sucrose as an osmotic response to their saline habitat together with manipulation of transport and secretion genes [163].
The biodegradable plastic such as PHB can be produced by Rhodovulum sulfidophilum P5 using inexpensive nitrogen and carbon sources [164]. PHB can be also produced in the filamentous cyanobacterium Nostoc muscorum under phosphate limitation by recombinant Synechocystis sp. PCC6803 [165] (Table 1). Glycogen can be produced in halophilic bacterium $A$. palentensis by manipulating growth condition [166]. Even ammonia can be produced by nitrogen-fixing cyanobacteria Anabaena sp. ATCC 33047 [167].

\section{Cultivation and harvesting methods Raceway pond}

Microalgae can use sunlight more efficiently than other crop plants to produce oil [168]. The oil production capacity is almost one or two times higher than any other crop [169]. The open pond system is better for large-scale production. The main disadvantage of open pond systems is that by being open to the atmosphere, they lose water by evaporation at a rate similar to land crops and are also susceptible to contamination [122,170]. Some protozoa may contaminate the system and hamper the growth of microalgae.

An effective culture system may consist of the following criteria: (1) effective illumination area, (2) optimal gas-liquid transfer, (3) easy to operate, (4) low contamination level, (5) low capital and production cost, and (6) minimal land area requirement [171]. The system can be made of paddle wheel to avoid microalgae biomass sedimentation, and $\mathrm{CO}_{2}$ may be sparged at the bottom of the raceway as carbon source [172]. 


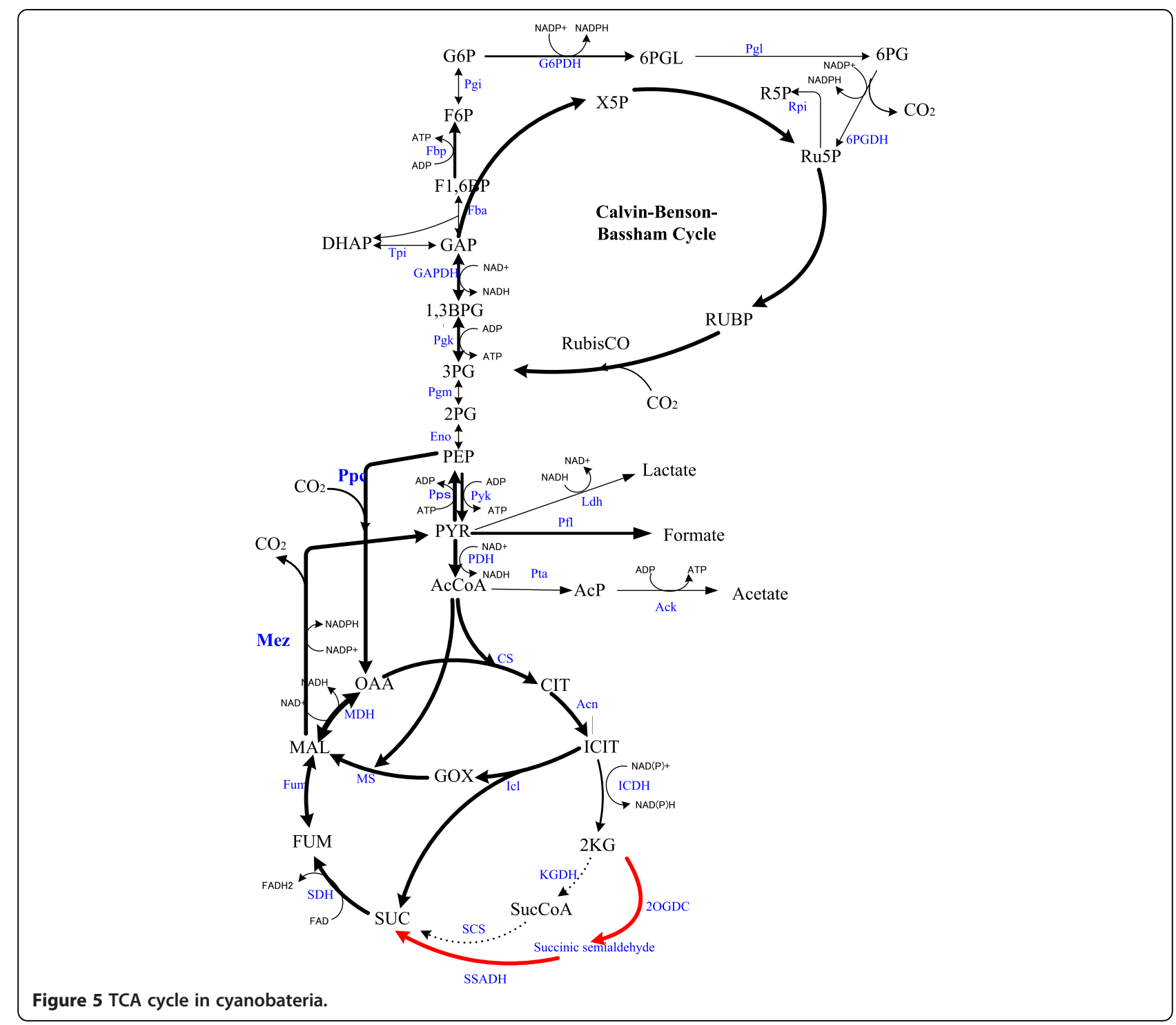

\section{Photobioreactor}

Closed photobioreactor may be considered to overcome the limitations encountered in raceway pond [170]. There are several designs of closed photobioreactor such as air-lift tubular, flat plate, and vertical-column reactors and culture parameters such as nutrient levels, temperature, amount of inlet $\mathrm{CO}_{2}$, etc. [173]. The reactor permits selective culture strain, in which optimum growth condition can be maintained to give high biomass and lipid productivity. The tubuler photobioreactor may be one of the most typical cultivation apparatus, where a vertical tubuler photobioreactor can increase the residence time of sparged gas, giving higher $\mathrm{CO}_{2}$ utilization efficiency [174]. The higher intensity of light cannot reach to most of the cell in the large-scale photobioreactor. As a consequence, the metabolism also changes from light to dark condition. This phenomenon is undesirable for large-scale production.

\section{Harvesting of algal biomass}

The microalgae need to be separated from water to recover their biomass for downstream processing. There are several methods for microalgae harvest: (1) bulk harvesting- to separate microalgae from suspension such as natural gravity sedimentation, flocculation, and floatation, and (2) thickening to concentrate the microalgae slurry after bulk harvesting such as centrifugation and filtration [169].

Flocculation, the aggregation and sedimentation (or flocculation) of algal biomass, is also a very common primary harvesting method used to concentrate algae. Algal strains can also be engineered such that the addition of a polymer or a change in an environmental variable triggers flocculation $[175,176]$.

Conventional flocculation method poses several disadvantages: (1) high dosage of multivalent slat is required 
to achieve satisfactory result, (2) it produces large quantity of sludge that increases the difficulty to dehydrate the biomass, and (3) flocculation efficiency is highly dependent on $\mathrm{pH}$ level $[169,177]$. By introduction of a coagulant that is positively charged into the culture medium, the negative charge surrounding the microalgae cells will be neutralized. At the same time, flocculant can be added to promote agglomeration by creating bridges between the neutralized cells to become dense flocs and settle down due to natural gravity [178]. Another possible method to harvest microalgae is through immobilization, in which microalgae are embedded in an entrapment matrix and continuously grow within the matrix. Only alginate gel entrapment method is feasible to immobilize microalgae so far [179]. Some of the advantages of using alginate gel are the requirement of only mild condition during immobilization process with negligible toxicity and high transparency $[179,180]$. Immobilized microalgae beads can be applied in diverse research areas such as for high-value product synthesis, organic pollutant removal, heavy metal removal, and toxicity measurement (biosensor) [180-186]. A few issues need to be addressed in immobilization of microalgae before the process can be upgraded to commercialization stage such as (1) stability, (2) leakage of microalgae cells, and (3) mass transfer limitation.

\section{Downstream processing \\ Oil extraction}

Effective lipid extraction is required particularly for microalgae with low lipid content, since the loss of the lipid during extraction process brings a serious problem for the production cost of microalgae biofuels [187]. The energy consumed in lipid extraction from dried microalgae biomass is a relatively small portion to the overall energy $[172,188]$. Various cell disruption methods are microwave application, sonication, bead beating, autoclaving $[189,190]$, grinding, osmotic shock, homogenization, freeze drying [189], and $10 \%(w / v) \mathrm{NaCl}$ addition $[190,191]$.

\section{Solvent extraction method}

The solvent must be inexpensive, nontoxic, volatile, nonpolar, and it must selectively extract the lipid of the cell [189]. The potential of using co-solvent mixtures of ionic liquids and polar covalent molecules has been shown for lipid extraction [192]. The Soxhlet extraction method uses hexane, while the Bligh and Dyer's method uses mixture of chloroform and methanol as solvents to extract lipids [193]. The other solvents include benzene and ether, but hexane has gained more popularity as a chemical for solvent extraction, and it is also relatively inexpensive [194]. Although n-hexane is widely used to extract oil from various seed crops, it is inefficient to extract microalgae lipid. This is because microalgae lipid contains high concentration of unsaturated fatty acid, while n-hexane is a nonpolar solvent. Thus the selectivity of lipid towards the solvent is reduced [187]. Methanol and n-hexane are not sustainable, since both solvents are conventionally derived from nonrenewable fossil fuels. On the other hand, ethanol is a greener solvent, since it has a low toxicity level and can be derived from renewable source such as sugar-based plant (e.g., sugar cane and sweet sorghum) and lignocellulosic material (e.g., weed and corn stover) [170]. The ethanol, however, gives low extraction efficiency. Ultrasonication and microwave can be also used for cell disruption. The cell wall-less mutant is better for oil extraction.

\section{Super critical fluid extraction}

Several supercritical fluids are $\mathrm{CO}_{2}$, ethane, methanol, ethanol, benzene, toluene, and water [195,196]. The basic principle of this technology is by achieving a certain phase (supercritical) that is beyond the critical point of a fluid, in which meniscus separating the liquid and vapor phase disappears, leaving only a single homogeneous phase [196]. Supercritical $\mathrm{CO}_{2}$ has received much interest typically in extraction of pharmaceutical and health-related products from microalgae [197-200]. In fact, supercritical $\mathrm{CO}_{2}$ offers several advantages in comparison with chemical solvent extraction such as (1) nontoxic and provide nonoxidizing environment to avoid degradation of extracts, (2) low critical temperature (around $31^{\circ} \mathrm{C}$ ) which prevents thermal degradation of products, (3) high diffusivity and low surface tension which allow penetration of pores smaller than those accessible by chemical solvents, and (4) easy separation of $\mathrm{CO}_{2}$ at ambient temperature after extraction $[195,197,200]$.

\section{Transesterification of oils}

The most suitable catalyst for transesterification of oils with low free fatty acids (FFA) content is necessary. The presence of high free fatty acid content in microalgae lipid (more than $0.5 \% \mathrm{w} / \mathrm{w}$ ) prevents the use of homogeneous base catalyst for transesterification reaction [201-203]. Alkaline metal alkoxides, even in small concentration of $0.5 \mathrm{~mol} \%$, are highly active catalysts [194]. Metal alkoxides (e.g., potassium methoxide) in methanol are better options than metal hydroxides $(\mathrm{NaOH}, \mathrm{KOH})$. In a short reaction time of about $30 \mathrm{~min}$, they give high yields of about 98\% [194]. They performed better in absence of water, which makes them inappropriate for industrial processes [204]. FFA will react with base catalyst to form soap leading to lower biodiesel yield and increase the difficulty to separate biodiesel from glycerol.

Acid catalyst (e.g., $\mathrm{H}_{2} \mathrm{SO}_{4}$ ) is not sensitive towards FFA level in oil, and thus esterificaiton (FFA is converted to alkyl ester) and transesterification can occur simultaneously. A chemically catalyzed transesterification process requires a high amount of energy, and separation of catalyst from the 
product is cost effective. Glycerol, produced as a byproduct of alcoholysis, readily adheres to the surface of immobilized lipase and decreases its enzyme activity, where glycerol removal is a complex process, which may hinder the largescale operations [189].

Free fatty acids contained in extracted oil have to be removed prior to reaction in order to maintain activity of the alkaline catalysts. In the superheated method, free fatty acid and triglycerides are converted to fatty acid methyl ester directly. Academic and commercial enterprises have realized the importance of such research on this topic, and a direct transesterification method for total microalgal lipid content has produced appreciable levels of biodiesel even when there are undetectable levels of neutral lipids $[205,206]$. The advantages of non-catalytic alcoholysis reaction for the production of biodiesel are as follows: (1) the purification process to remove catalyst after reaction is not required, (2) the by-product (glycerol) can be directly utilized in other industry, (3) not only the triglycerides but also the free fatty acid might be converted into fatty acid methyl ester, (4) neutralization process for removal of free fatty acid is not required prior to the reaction process, and (5) the yield of the total system will be improved, and the cost required for the process will be reduced.

\section{Improvement of product recovery}

In a large-scale operation, the presence of microorganisms, medium composition, and process condition may cause emulsion formation, which lowers the product recovery efficiency. A better understanding on the mechanism of emulsion formation is necessary for the performance improvement based on nanotechnology as well as electrochemical properties such as ion, charge, viscosity, interface stabilization [207].

\section{Conclusions}

The fluctuation in global prices of crude oil, increasing threats to the environment by exhaust emissions, global warming, and threats of supply instabilities have adversely impacted the developing countries, more so to the petroleum-importing countries. The rising of sea level caused by green-house gas $\left(\mathrm{CO}_{2}\right)$ also threatens the most populated areas of the world. It is important to find a safe alternative fuel to relieve the escalating energy crisis and to protect the environment. Photosynthetic microorganisms have emerged as one of the most promising sources for biodiesel production.

Although algae and cyanobacteria have been paid recent attention from the point of view of sustainable biosynthesis as well as biofuel and biochemical production, the cell growth rate is significantly lower as compared to the typical biofuel-producing microorganisms such as $E$. coli and yeast. It is, therefore, strongly desirable to design microbial cell factories by means of a synthetic biology approach with in-depth understanding of the metabolic regulation mechanism with the aid of a systems biology approach such as modeling.

Several attempts are being made for improving the efficiency of capturing light energy and $\mathrm{CO}_{2}$ fixation as mentioned before. One of the reasons of the lower cell growth rate in cyanobacteria may be due to an incomplete TCA cycle lacking KGDH and succinyl CoA synthetase (SCS). Recent investigation on Synecococcus sp. PCC7002 indicates that the genes encoding $\alpha K G$ decarboxylase (or 2-oxoglutarate decarboxylase) and succinic semialdehyde dehydrogenase are present, where NADPH instead of NADH is produced without producing guanosine triphosphate (GTP) by substrate level phosphorylation (Figure 5) [208]. It is important to elucidate the nature of such TCA cycles in cyanobacteria and plants from the point of view of functional significance of the metabolic feature in a broader evolutionary context [209]. Further investigation is necessary to improve the cell growth rate with balanced energy generation and biosynthesis.

\section{Competing interests}

The authors declare that they have no competing interests.

\section{Authors' contributions}

DS and KS investigated the references and drafted the manuscript. Both authors read and approved the final manuscript.

\section{Acknowledgements}

The authors would like to acknowledge Sheuli Bala for her helping during typing the manuscript.

\section{Author details}

'Department of Microbiology, Primeasia University, Banani, Dhaka 1213, Bangladesh. ${ }^{2}$ Kyushu Institute of Technology, lizuka, Fukuoka 820-8502, Japan. ${ }^{3}$ Institute of Advanced Bioscience, Keio University, Tsuruoka, Yamagata 997-0017, Japan.

Received: 24 December 2014 Accepted: 11 March 2015

Published online: 16 April 2015

\section{References}

1. Canadell JG, Schulze ED (2014) Global potential of biospheric carbon management for climate mitigation. Nature Commun 5:5282

2. Schmidt LD, Dauenhauer PJ (2007) Chemical engineering: hybrid routes to biofuels. Nature 447:914-915

3. Rodolfi L, Chini Zittelli G, Bassi N, Padovani G, Biondi N, Bonini G et al (2009) Microalgae for oil: Strain selection, induction of lipid synthesis and outdoor mass cultivation in a low-cost photobioreactor. Biotechnol Bioeng 102(1):100-112

4. Jones CS, Mayfield SP (2012) Algae biofuels: versatility for the future of bioenergy. Curr Opin Biotechnol 23(3):346-351

5. Scott SA, Davey MP, Dennis JS, Horst I, Howe CJ, Lea-Smith DJ et al (2010) Biodiesel from algae: challenges and prospects. Curr Opin Biotechnol 21(3):277-286

6. Smil V (2005) Energy at the Crossroads: Global perspectives and uncertainties. MIT press.

7. Larkum AWD, Ross IL, Kruse O, Hankamer B (2012) Selection, breeding and engineering of microalgae for bioenergy and biofuels production. Trends Biotechnol 30(4):198-205

8. Stephens Al (2010) Influence of nitrogen-limitation regime on the production by Chlorella vulgaris of lipids for biodiesel feedstocks. Biofuels 1:47-58 
9. Larkum AWD (2010) Limitations and prospects of natural photosynthesis for bioenergy production. Curr Opin Biotechnol 21:271-276

10. Zhu XG, Long SP, Ort DR (2010) Improving photosynthetic efficiency for greater yield. Annu Rev Plant Biol 61:235-261

11. Beer C, Reichstein M, Tomelleri E, Ciais P, Jung M, Carvalhais N et al (2010) Terrestrial gross carbon dioxide uptake: global distribution and covariation with climate. Science 329:834-838

12. Yuan L, Grotewold E (2015) Metabolic engineering to enhance the value of plants as green factories. Metab Eng 27:83-91

13. Overmann J, Garcia-Pichel F (2006) The photosynthetic way of life. In: Dworkin M, Falkow S (eds) The procaryotes: A handbook on the biology of bacteria, vol 2. Springer, NewYork, pp 32-85

14. Shimizu K (2014) Biofuels and biochemical production by microbes, Nova Publ. Co.

15. Sheehan J (2009) Engineering direct conversion of $\mathrm{CO}_{2}$ to biofuel. Nat Biotechnol 27:1128-1129

16. Savakis $P$, Hellingwerf KJ (2015) Engineering cyanobacteria for direct biofuel production from $\mathrm{CO}_{2}$. Curr Opin Biotechnol 33:8-14

17. Yu J (2014) Bio-based products from solar energy and carbon dioxide. Trends Biotechnol 32(1):5-10

18. Khan SA, Hussain MZ, Prasad S, Banerjee UC (2009) Prospects of biodiesel production from microalgae in India. Renew Sustain Energy Rev 13(9):2361-2372

19. Chisti Y (2007) Biodiesel from microalgae. Biotechnol Adv 25:294-306

20. Mata TM, Martins AA, Caetano NS (2010) Microalgae for biodiesel production and other applications: a review. Renew Sustain Energy Rev 14:217-232

21. Georgianna DR, Mayfield SP (2012) Exploiting diversity and synthetic biology for the production of algal biofuels. Nature 488:329-335

22. Wijffels RH, Barbosa MJ (2010) An outlook on microalgal biofuels. Science 329:796-799

23. Boyle NR, Morgan JA (2009) Flux balance analysis of primary metabolism in Chlamydomonas reinhardtii. BMC Syst Biol 3(1):4

24. Chiu SY, Kao CY, Chen CH, Kuan TC, Ong SC, Lin CS (2008) Reduction of $\mathrm{CO}_{2}$ by a high-density culture of Chlorella sp. in a semicontinuous photobioreactor. Bioresour Technol 99(9):3389-3396

25. Rosenberg JN, Mathias A, Korth K, Betenbaugh MJ, Oyler GA (2011) Microalgal biomass production and carbon dioxide sequestration from an integrated ethanol biorefinery in lowa: A technical appraisal and economic feasibility evaluation. Biomass Bioenergy 35(9):3865-3876

26. Sydney EB, Sturm W, de Carvalho JC, Thomaz-Soccol V, Larroche C, Pandey A et al (2010) Potential carbon dioxide fixation by industrially important microalgae. Bioresour Technol 101(15):5892-5896

27. Yoo C, Jun SY, Lee JY, Ahn CY, Oh HM (2010) Selection of microalgae for lipid production under high levels carbon dioxide. Bioresour Technol 101(1):S71-S74

28. Zhao B, Zhang Y, Xiong K, Zhang Z, Hao X, Liu T (2011) Effect of cultivation mode on microalgal growth and $\mathrm{CO}_{2}$ fixation. Chem Eng Res Des 89 (9):1758-1762

29. Rosenberg JN, Oyler GA, Wilkinson L, Betenbaugh MJ (2008) A green light for engineered algae: redirecting metabolism to fuel a biotechnology revolution. Curr Opin Biotechnol 19(5):430-436

30. O'Grady J, Schwender J, Shachar-Hill Y, Morgan JA (2012) Metabolic cartography: experimental quantification of metabolic fluxes from isotopic labelling studies. J Exp Bot 63(6):2293-2308

31. Dennis DT, Blakeley SD (2000) Carbohydrate metabolism. In: Buchanan BB, Gruissem W, Jones RL (eds) Biochemistry and Molecular Biology of Plants. American Society of Plant Physiologists, Rockville MD, pp 630-675

32. Sriram G, Fulton DB, lyer W, Peterson JM, Zhou R, Westgate ME et al (2004) Quantification of compartmented metabolic fluxes in developing soybean embryos by employing biosynthetically directed fractional ${ }^{13} \mathrm{C}$ labeling, two-dimensional $[13 \mathrm{C}, 1 \mathrm{H}]$ nuclear magnetic resonance, and comprehensive isotopomer balancing. Plant Physiol 136(2):3043-3057

33. Sriram G, Iyer W, Bruce Fulton D, Shanks JV (2007) Identification of hexose hydrolysis products in metabolic flux analytes: A case study of levulinic acid in plant protein hydrolysate. Metab Eng 9(5):442-451

34. Schwender J, Shachar-Hill Y, Ohlrogge JB (2006) Mitochondrial metabolism in developing embryos of Brassica napus. J Biol Chem 281(45):34040-34047

35. Allen DK, Shachar-Hill Y, Ohlrogge JB (2007) Compartment-specific labeling information in ${ }^{13} \mathrm{C}$ metabolic flux analysis of plants. Phytochem 68(16):2197-2210
36. Lonien J, Schwender J (2009) Analysis of metabolic flux phenotypes for two Arabidopsis mutants with severe impairment in seed storage lipid synthesis. Plant Physiol 151(3):1617-1634

37. Gerhardt R, Stitt M, Heldt HW (1983) Subcellular metabolite determination in spinach leaves through non-aqueous fractionation. Physiol Chem 364:1130-1131

38. Masakapalli SK, Le Lay P, Huddleston JE, Pollock NL, Kruger NJ, Ratcliffe RG (2010) Subcellular flux analysis of central metabolism in a heterotrophic Arabidopsis cell suspension using steady-state stable isotope labeling. Plant Physiol 152(2):602-619

39. Hu Q, Sommerfeld M, Jarvis E, Ghirardi M, Posewitz M, Seibert M et al (2008) Microalgal triacylglycerols as feedstocks for biofuel production: perspectives and advances. Plant J 54(4):621-639

40. Bigogno C, Khozin-Goldberg I, Boussiba S, Vonshak A, Cohen Z (2002) Lipid and fatty acid composition of the green oleaginous alga Parietochloris incisa, the richest plant source of arachidonic acid. Phytochem 60(5):497-503

41. Radakovits R, Jinkerson RE, Darzins A, Posewitz MC (2010) Genetic engineering of algae for enhanced biofuel production. Eukaryot Cell 9(4):486-501

42. Harris EH (2009) The Chlamydomonas sourcebook: introduction to Chlamydomonas and its laboratory use Vol. 1, Acad Press.

43. Wang ZT, Ullrich N, Joo S, Waffenschmidt S, Goodenough U (2009) Algal lipid bodies: stress induction, purification, and biochemical characterization in wildtype and starchless Chlamydomonas reinhardtii. Eukaryot Cell 8(12):1856-1868

44. Work VH, Radakovits R, Jinkerson RE, Meuser JE, Elliott LG, Vinyard DJ et al (2010) Increased lipid accumulation in the Chlamydomonas reinhardtii sta7-10 starchless isoamylase mutant and increased carbohydrate synthesis in complemented strains. Eukaryot Cell 9(8):1251-1261

45. Siaut M, Cuiné S, Cagnon C, Fessler B, Nguyen M, Carrier P et al (2011) Oil accumulation in the model green alga Chlamydomonas reinhardtii: characterization, variability between common laboratory strains and relationship with starch reserves. BMC Biotechnol 11(1):7

46. Moellering ER, Benning C (2010) RNA interference silencing of a major lipid droplet protein affects lipid droplet size in Chlamydomonas reinhardtii. Eukaryot Cell 9(1):97-106

47. Li Y, Han D, Hu G, Dauvillee D, Sommerfeld M, Ball S et al (2010) Chlamydomonas starchless mutant defective in ADP-glucose pyrophosphorylase hyper-accumulates triacylglycerol. Metab Eng 12(4):387-391

48. Merchant SS, Kropat J, Liu B, Shaw J, Warakanont J (2012) TAG, You're it! Chlamydomonas as a reference organism for understanding algal triacylglycerol accumulation. Curr Opin Biotechnol 23(3):352-363

49. Liu B, Benning C (2013) Lipid metabolism in microalgae distinguishes itself. Curr Opin Biotechnol 24(2):300-309

50. Cagnon C, Mirabella B, Nguyen HM, Beyly-Adriano A, Bouvet S, Cuiné S et al (2013) Development of a forward genetic screen to isolate oil mutants in the green microalga Chlamydomonas reinhardtii. Biotechnol Biofuels 6(1):178

51. Solovchenko AE, Khozin-Goldberg I, Didi-Cohen S, Cohen Z, Merzlyak MN (2008) Effects of light intensity and nitrogen starvation on growth, total fatty acids and arachidonic acid in the green microalga Parietochloris incise. J Appl Phycol 20(3):245-251

52. Harun R, Danquah MK, Forde GM (2010) Microalgal biomass as a fermentation feedstock for bioethanol production. J Chem Technol Biotechnol 85(2):199-203

53. Yacoby I, Pochekailov S, Toporik H, Ghirardi ML, King PW, Zhang S (2011) Photosynthetic electron partitioning between [FeFe]-hydrogenase and ferredoxin: NADP + -oxidoreductase (FNR) enzymes in vitro. PNAS USA 108(23):9396-9401

54. Park JH, Yoon JJ, Park HD, Kim YJ, Lim DJ, Kim SH (2011) Feasibility of biohydrogen production from Gelidium amansii. Int J Hydrogen Energy 36(21):13997-14003

55. Shi X, Jung KW, Kim DH, Ahn YT, Shin HS (2011) Direct fermentation of Laminaria japonica for biohydrogen production by anaerobic mixed cultures. Int J Hydrogen Energy 36(10):5857-5864

56. Peers $\mathrm{G}$ (2014) Increasing algal photosynthetic productivity by integrating ecophysiology with systems biology. Trends Biotechnol 32(11):551-555

57. Sage RF, Sage TL, Kocacinar F (2012) Photorespiration and evolution of C4 photosynthesis. Annu Rev Plant Biol 63:19-47

58. Wang L, Czedik-Eysenberg A, Mertz RA, Si Y, Tohge T, Nunes-Nesi A et al (2014) Comparative analysis of $C_{4}$ and $C_{3}$ photosynthesis in developing leaves of maize and rice. Nat Biotechnol 32(11):1158-1165 
59. Ducat DC, Silver PA (2012) Improving carbon fixation pathways. Curr Opin Chem Bol 16:337-344

60. Savage DF, Afonso B, Chen AH, Silver PA (2010) Spatially ordered dynamics of the bacterial carbon fixation machinery. Science 327:1258-1261

61. Atsumi S, Higashide W, Liao JC (2009) Direct photosynthetic recycling of carbon dioxide to isobutyraldehyde. Nat Biotechnol 27:1177-1180

62. Genkov T, Meyer M, Griffiths H, Spreitzer RJ (2010) Functional hybrid rubisco enzymes with plant small subunits and algal large subunits: engineered rbsC cDNA for expression in Chlamidomonas. J Biol Chem 285:19833-19841

63. Banti V, Giuntoli B, Gonzali S, Loreti E, Magneschi L, Novi G et al (2013) Low oxygen response mechanisms in green organisms. Int J Mol Sci 14:1-30

64. Geigenberger P (2003) Response of plant metabolism to too little oxygen. Curr Opin Plant Biol 6:247-256

65. Veyel D, Erban A, Fehrle I, Kopka J, Schroda M (2014) Rationals and approaches for studying metabolism in eukaryotic microalgae. Metabolites 4:184-217

66. Mettler T, Mühlhaus T, Hemme D, Schöttler MA, Rupprecht J, Idoine A et al (2014) Systems analysis of the response of photosynthesis, metabolism and growth to an increase in irradiance in the photosynthetic model organism Chlamydomonas reinhardtii. Plant Cell 26:2310-2350

67. Yang C, Hua Q, Shimizu K (2000) Energetics and carbon metabolism during growth of microalgal cells under photoautotrophic, mixotrophic and cyclic light-autotrophic/dark-heterotrophic conditions. Biochem Eng J 6(2):87-102

68. Quintana N, van der Kooy F, van der Rhee MD, Voshol GP, Verpoorte R (2011) Renewable energy from Cyanobacteria: energy production optimization by metabolic pathway engineering. Appl Microbiol Biotechnol 91:471-490

69. Pearce J, Leach CK, Carr NG (1969) The incomplete tricarboxylic acid cycle in the blue-green alga Anabaena variabilis. J Gen Microbiol 55:371-378

70. Vazquez-Bermudex MF, Herrero A, Flores E (2000) Uptake of 2-oxoglutarate in Synechococcus strain transformed with the Escherichia coli kgtP gene. J Bacteriol 182:211-215

71. Pearce J, Carr NG (1967) The metabolism of acetate by the blue-green algae, Anabaena variabilis and Anacystis nidulans. J Gen Microbiol 49:301-313

72. Yang C, Hua Q, Shimizu K (2002) Quantitative analysis of intracellular metabolic fluxes using GC-MS and two-dimensional NMR spectroscopy. J Biosci Bioeng 93(1):78-87

73. Yang C, Hua Q, Shimizu K (2002) Metabolic flux analysis in Synechocystis using isotope distribution from ${ }^{13} \mathrm{C}$-labeled glucose. Metab Eng 4(3):202-216

74. Yang C, Hua Q, Shimizu K (2002) Integration of the information from gene expression and metabolic fluxes for the analysis of the regulatory mechanisms in Synechocystis. Appl Microbiol Biotechnol 58(6):813-822

75. Schwender $J$ (2008) Metabolic flux analysis as a tool in metabolic engineering of plants. Curr Opin Biotechnol 19:131-137

76. Wiechert W, Noh K (2005) From stationary to instationary metabolic flux analysis. Adv Biochem Eng Biotechnol 92:145-172

77. Young JD, Shastri AA, Stephanopoulos G, Morgan JA (2011) Mapping photoautotrophic metabolism with isotopically nonstatinary ${ }^{13} \mathrm{C}$ flux analysis. Metab Eng 13:656-665

78. Colman B, Norman EG (1997) Serine synthesis in cyanobacteria by a nonphotorespiratory pathway. Physiol Plant 100:133-136

79. Owittrim GW, Colman B (1988) Phosphoenolpyruvate carboxylase mediated carbon flow in a cyanobacterium. Biochem Cell Biol 66:93-99

80. Bricker TM, Zhang S, Laborde SM, Mayer II PR, Frankel LK, Moroney JV (2004) The malic enzyme is required for optimal photoautotrophic growth of Synechocystis sp. strain PCC6803 under continuous light but not under a diurnal light regimen. J Bacteriol 186(23): 8144-8148

81. StompM HJ, Voros L, Pick FR, Laamanen M, Haverkamp T, Stal L (2007) Colourful coexistence of red and green picocyanobacteria in lakes and seas. Ecol Lett 10:290-298

82. Griffiths MJ et al (2009) Lipid productivity as a key characteristic for choosing algal species for biodiesel production. J Appl Phycol 21:493-507

83. Klok AJ, Lamers PP, Martens DE, Draaisma RB, Wijffels RH (2014) Edible oils from microalgae: insights in TAG accumulation. Trends Biotechnol 32(10):521-528

84. Blaby IK, Glaesener AG, Mettler T, Fitz-Gibbon ST, Gallaher SD, Liu B et al (2013) Systems-level analysis of nitrogen starvation-induced modifications of carbon metabolism in a Chlamydomonas reinhardtii starchless mutant. Plant Cell 25:4305-4323

85. Flores $E$, Herrero A (2005) Nitrogen assimilation and nitrogen control in cyanobacteria. Biochem Soc Trans 33:164-167
86. Valladares A, Montesinos ML, Herrero A, Flores E (2002) An ABC-type, high-affinity urea permease identified in cyanobacteria. Mol Microbiol 43:703-715

87. Garcia-Fernandez JM, de Marsac NT, Diez J (2004) Streamlined regulation and gene loss as adaptive mechanisms in Prochlorococcus for optimized nitrogen utilization in oligotrophic environments. Microbiol Mol Biol Rev 68:630-638

88. Allen MM (1984) Cyanobacterial cell inclusions. Annu Rev Microbiol 38:1-25

89. Li H, Sherman DM, Bao S, Sherman LA (2001) Pattern of cyanophycin accumulation in nitrogen-fixing and non-nitrogen-fixing cyanobacteria anobacteria. Arch Microbiol 176:9-18

90. Grossman AR, Schaefer MR, Chiang GG, Collier JL (1993) The phycobilisome, a light-harvesting complex responsive to environmental conditions. Microbiol Rev 57:725-749

91. Dong HP, Williams E, Wang DZ, Xie ZX, Hsia RC, Jenck A et al (2013) Responses of Nanochloropsis oceanica IMET1 to long-term nitrogen starvation and recovery. Plant Physiol 162:1110-1126

92. Li H, Sherman LA (2002) Characterization of Synechocystis sp. Strain PCC6803 and deltanbl mutants under nitrogen-deficient conditions. Arch Microbiol 178:256-266

93. Baier K, Nicklisch S, Grundner C, Reinecke J, Lockau W (2001) Expression of two nblA-homologous genes required for phycobilisome degradation in nitrogen-starved Synechocystis sp. PCC6803. FEMS Microbiol Lett 195:35-39

94. Kiyota H, Yokota-Hirai M, Ikeuchi M (2014) NbIA1/A2-dependent homeostasis of amino acid pools during nitrogen starvation in Synechocystis sp. PCC6803. Metabolites 4:517-531

95. Schwarz D, Orf I, Kopla J, Hagemann M (2014) Effects of inorganic carbon limitation on the metabolome of the Synechocystis sp. PCC6803 mutant defective in glnB encoding the central regulator PII of cyanocacterial C/N acclimation. Metabolites 4:232-247

96. Azuma M, Osanai T, Hirai MY, Tanaka K (2011) A response regulator Rre37 and an RNA polymerase sigma factor SigE represent two parallel pathways to activate sugar catabolism in a cyanobacterium Synechocystis sp. PCC 6803. Plant Cell Physiol 52:404-412

97. Ehira S, Ohmori M (2006) NrrA directly regulates expression of hetR during heterocyst differentiation in the cyanobacterium Anabaena sp. strain PCC 7120. J Bacteriol 188:8520-8525

98. Liu D, Yang C (2014) The nitrogen-regulated response regulator NrrA controls cyanophicin synthesis and glycogen catabolism in the cyanobacterium Synechocystis sp. PCC 6803. J Biol Chem 289(4):2055-2071

99. Krasikov V, von Wobeser AE, Dekker HL, Huisman J, Matthijs HC (2012) Time-series resolution of gradual nitrogen starvation and its impact on photosynthesis in the cyanobacterium Synechocystis PCC 6803. Physiol Plant 145:426-439

100. Markou G, Nerantzis E (2013) Microalgae for high-value compounds and biofuels production: A review with focus on cultivation under stress conditions. Biotechnol Adv 31:1532-1542

101. Miyake M, Kataoka K, Shirai M, Asada Y (1997) Control of poly- $\beta$ hydroxybutyrate synthase mediated by acetyl phosphate in cyanobacteria. J Bacteriol 179:5009-503

102. Hauf W, Schlebusch M, Huge J, Kopka J, Hagemann M, Forchhammer K (2013) Metabolic changes in Synechocystis PCC6803 upon nitrogen-starvation: Excess NADPH sustains polyhydroxybutyrate accumulation. Metabolites 3:101-118

103. Muro-Pastor AM, Herrero A, Flores E (2001) Nitrogen-regulated group 2 sigma factor from Synechocystis sp. Strain PCC6803 involved in survival under nitrogen stress. J Bacteriol 183:1090-1095

104. Osanai T, Kanesaki Y, Nakano T, Takahashi H, Asayama M, Shirai M et al (2005) Positive regulation of sugar catabolic pathways in the cyanobacterium Synechocystis sp. PCC 6803 by the group 2 sigma factor sigE. J Biol Chem 280:30653-30659

105. Osanai T et al (2011) Genetic engineering of group 2 sigma factor SigE widely activates expressions of sugar catabolic genes in Synechocystis sp. PCC 6803. J Biol Chem 286:30962-30971

106. Osanai T, Numata K, Oikawa A, Kuwahara A, lijima H, Doi Y et al (2013) Increased bioplastic production with an RNA polymerase sigma factor SigE during nitrogen starvation in Synechocystis sp. PCC6803. DNA Res 20:525-535

107. Osanai T, Kuwahara A, lijima H, Toyooka K, Sato M, Tanaka K et al (2013) Pleiotropic effect of sigE over-expression on cell morphorogy, photosynthesis, and hydrogen production in Synechocystis sp. PCC6803.

Plant J 76:456-465 
108. Wada N, Sakamoto T, Matsugo S (2013) Multiple roles of photosynthetic and sunscreen pigments in cyanobacteria focusing on the oxidative stress. Metabolites 3:463-483

109. Reijnders MJMF, van Heck RGA, Lam CMC, Scaife MA, Martins dos Santos VAP, Smith AG et al (2014) Green genes: bioinformatics and systems-biology innovations drive algal biotechnology. Trends Biotechnol 32(12):617-626

110. Poolman MG, Fell DA, Thomas S (2000) Modeling photosynthesis and its control. J Exp Bot 51:319-328

111. Poolman MG, Olcer H, Lloyd JC, Raines CA, Fell DA (2001) Computer modeling and experimental evidence for two steady states in the photosynthetic Carbin cycle. Eur J Biochem 268:2810-2816

112. Garcia-Camacho F, Sanchez-Miron A, Morina-Grima E, Camacho-Rubio F, Merchuck JC (2012) A mechanistic model of photosynthesis in microalgae including photoacclimation dynamics. J Theor Biol 304:1-15

113. Camacho-Rubio F, Garcia-Camacho F, Fernandez-Sevilla JM, Chisty Y, Grima E (2003) A mechanistic model of photosynthesis in microalgae. Biotechnol Bioeng 81:459-473

114. Gerin S, Mathy G, Franck F (2014) Modeling the dependence of respiration and photosynthesis upon light, acetate, carbon dioxide, nitrate and ammonium in Chlamydomonas reinhardtii using design of experiments and multiple regression. BMC Sys Biol 8:96

115. Kliphuis AMJ, Klok AJ, Martens DE, Lamers PP, Janssen M, Wijffels RH (2012) Metabolic modeling of Chlamydomonas reinhardtii: Energy requirements for autotrophic growth and maintenance. J Appl Phycol 24:253-266

116. Cogne G, Rugen M, Bockmayr A, Titica M, Dussap C-G, Cornet J-F et al (2011) A model-based method for investigating bioenergetics processes in autotrophically growing eukaryotic microalgae: Application to the green algal Chlamydomonas reinhardtii. Biotechnol Prog 27(3):631-640

117. Boyle NR, Morgan JA (2009) Flux balance analysis of primary metabolism in Chlamydomonas reinhardtii. BMC Sys Biol 3:4

118. Chang RL, Ghamsari L, Manichaikul A, Hom EFY, Balaji S, Fu W et al (2011) Metabolic network reconstruction of Chlamydomonas offers insight into light-driven algal metabolism. Mol Sys Biol 7:518

119. de Oliveira Dal'Molin CG, Quek L-E, Palfreyman RW, Nielsen LK (2011) AlgaGEM^a genome-scale metabolic reconstruction of algae based on the Chalamydomonas reinhardtii genome. BMC Genomics 12: (Suppl 4) S5

120. Knoop H, Grundel M, Zilliges Y, Lehmann R, Hoffmann S, Lockau W, Steuer $R$ (2013). Flux balance analysis of cyanobacterial metabolism: The metabolic network of Synechocyctis sp. PCC6803. Plos Comp Biol;9(6): 21003081

121. Triana J, Montagud A, Siurana M, Fuente D, Urchueguia A, Gamermann D et al (2014) Generation and evaluation of a genome-scale metabolic network model of Synechococcus elongatus PCC7942. Metabolites 4:680-698

122. Schenk PM, Thomas-Hall SR, Stephens E, Marx UC, Mussgnug JH, Posten C et al (2008) Second generation biofuels: high-efficiency microalgae for biodiesel production. Bioenergy Res 1(1):20-43

123. Lacour T, Sciandra A, Talec A, Mayzaud P, Bernard O (2012) Disel variations of carbohydrates and neutral lipids in nitrogen-sufficient and nitrogenstarved cyclostat cultures of Isochrysis sp. 1. J Geophys Res 48(4):966-975

124. Kilian O, Benemann CS, Niyogi KK, Vick B (2011) High-efficiency homologous recombination in the oil-producing alga Nannochloropsis sp. PNAS USA 108(52):21265-21269

125. Singh A, Nigam PS, Murphy JD (2011) Renewable fuels from algae: an answer to debatable land based fuels. Bioresour Technol 102(1):10-16

126. James CN, Horn PJ, Case CR, Gidda SK, Zhang D, Mullen RT et al (2010) Disruption of the Arabidopsis CGI-58 homologue produces Chanarin-Dorfmanlike lipid droplet accumulation in plants. PNAS USA 107(41):17833-17838

127. Dexter J, Fu PC (2009) Metabolic engineering of cyanobacteria for ethanol production. Energy Environ Sci 2:857-864

128. Dienst D, Georg J, Abts T, Jakorew L, Kuchmina E, Borner T, Wilde A, Duhring U, Enke H, Hess WR (2014) Transcriptomic response to prolonged ethanol production in the cyanobacterium Synechosystis sp. PCC6803. Biotechnol for Biofuels 7:21

129. Atsumi S, Liao JC (2008) Directed evolution of Methanococcus jannaschii citramalate synthase for biosynthesis of 1-propanol and 1-butanol by Escherichia coli. Appl Environ Microbiol 74:7802-7808

130. Shen CR, Liao JC (2012) Photosynthetic production of 2-methyl-1-butanol from $\mathrm{CO}_{2}$ in cyanobacterium Synechococcus elongatus PCC 7942 and characterization of the native acetohydroxyacid synthase. Energy Environ Sci $5: 9574$
131. Lan El, Liao JC (2011) Metabolic engineering of cyanobacteria for 1-butanol production from carbon dioxide. Metab Eng 13:353-363

132. Lan El, Liao JC (2012) ATP drives direct photosynthetic production of 1-butanol in cyanobacteria. PNAS USA 109:6018-6023

133. Wang Y, Shi M, Niu X, Zhang X, Gao L, Chen L et al (2014) Metabolomic evolution of butanol tolerance in photosynthetic Synechocystis sp. PCC6803. Microb Cell Fact 13:151

134. Datta R, Henry M (2006) Recent advances in products, processes and technologies-a review. J Chem Technol Biotechnol 81:1119-1129

135. Niederholtmeyer H, Wolfstadter BT, Savage DF, Silver PA, Way JC (2010) Engineering cyanobacteria to synthesize and export hydrophilic products. Appl Environ Microbiol 76:3462-3466

136. Angermayr SA, van der Woude AD, Correddu D, Vreugdenhil A, Verrone V, Hellingwerf KJ (2014) Exploring metabolic engineering design principles for the photosynthetic production of lactic acid by Synechosystis sp. PCC6803. Biotechnol for Biofuels 7:99

137. Richter N, Zienert A, Hummel W (2011) A single-point mutation enables lactate dehydrogenage from Bacillus subtilis to utilize $\mathrm{NAD}^{+}$and $\mathrm{NADP}^{+}$as cofactor. Eng Lif Sci 11:26-36

138. Lindberg P, Park S, Melis A (2010) Engineering a platform for photosynthetic isoprene production in cyanobacteria, using Synechocystis as the model organism. Metab Eng 12:70-79

139. Ungerer J, Tao L, Davis M, Ghirardi M, Maness PC, Yu JP (2012) Sustained photosynthetic conversion of $\mathrm{CO}_{2}$ to ethylene in recombinant cyanobacterium Synechocystis 6803. Energy Environ Sci 5:8998-9006

140. Gao Q, Wang W, Zhao H, Lu X (2012). Effects of fatty acid activation on photosynthetic production of fatty acid-based biofuels in Synechocystis sp. PCC6803. Biotechnol for Biofuels; 5:17

141. Liu X, Fallon S, Sheng J, Curtiss R 3rd (2011) $\mathrm{CO}_{2}$-limitation-inducible Green Recovery of fatty acids from cyanobacterial biomass. PNAS USA 108:6905-6908

142. Liu X, Sheng J, Curtiss R 3rd (2011) Fatty acid production in genetically modified cyanobacteria. PNAS USA 108:6899-6904

143. Tan X, Yao L, Gao Q, Wang W, Qi F, Lu X (2011) Photosynthesis driven conversion of carbon dioxide to fatty alcohols and hydrocarbons in cyanobacteria. Metab Eng 13:169-176

144. Sivakumar G, Xu J, Thompson RW, Yang Y, Randol-Smith P, Weathers PJ (2012) Integrated green algal technology for bioremediation and biofue. Bioresour Technol 107:1-9

145. Rasala BA, Chao S-S, Pier M, Barrera DJ, Mayfield SP (2014) Enhanced genetic tools for engineering multigene traits into green algae. PLoS One 9(4):e94028

146. Lei A, Chen H, Shen G, Hu Z, Chen L, Wang J (2012) Expression of fatty acid synthesis genes and fatty acid accumulation in haematococcus pluvialis under different stressors. Biotechnol Biofuels 5:18

147. Anandarajah K, Mahendraperumal G, Sommerfeld M, Hu Q (2012) Characterization of microalga Nannochloropsis sp. mutants for improved production of biofuels. Appl Energy 96:371-377

148. Zhou J, Zhang H, Zhang Y, Li Y, Ma Y (2012) Designing and creating a modularized synthetic pathway in cyanobacterium Synechocystis enables production of acetone from carbon dioxide. Metab Eng 14:394-400

149. Mendez-Perez D, Begemann MB, Pfleger BF (2011) Modular synthase-encoding gene involved in alpha-olefin biosynthesis in Synechococcus sp. strain PCC 7002. Appl Environ Microbiol 77:4264-4267

150. Gunther A, Jakob T, Goss R, Konig S, Spindler D, Rabiger N et al (2012) Methane production from glycolate excreting algae as a new concept in the production of biofuels. Bioresour Technol 121:454-457

151. Kobayashi J, Hasegawa S, Ito K, Yoshimune K, Komoriya T, Asada A et al (2012) Expression of aldehyde dehydrogenase gene increases hydrogen production from low concentration of acetate by Rhodobacter sphaeroides. Int J Hydrogen Energy 37:9602-9609

152. Lo SC, Shih SH, Chang JJ, Wang CY, Huang CC (2012) Enhancement of photoheterotrophic biohydrogen production at elevated temperatures by the expression of a thermophilic clostridial hydrogenase. Appl Microbiol Biotechnol 95:969-977

153. Ducat DC, Sachdeva G, Silver PA (2011) Rewiring hydrogenase-dependent redox circuits in cyanobacteria. PNAS USA 108:3941-3946

154. Ananyev GM, Skizim NJ, Dismukes GC (2012) Enhancing biological hydrogen production from cyanobacteria by removal of excreted products. J Biotechnol 162:97-104 
155. Havel J, Weuster-Botz D (2007) Cofactor regeneration in phototrophic cyanobacteria applied for asymmetric reduction of ketones. Appl Microbiol Biotechnol 75:1031-1037

156. Nakamura K, Tohi YR, Hamada KH (2000) Cyanobacterium-catalyzed asymmetric reduction of ketones. Tetrahedron Lett 41:6799-6802

157. Yang ZH, Luo L, Chang X, Zhou W, Chen GH, Zhao Y et al (2012) Production of chiral alcohols from prochiral ketones by microalgal photo-biocatalytic asymmetric reduction reaction. J Ind Microbiol Biotechnol 39:835-841

158. Hajimahmoodi M, Faramarzi MA, Mohammadi N, Soltani N, Oveisi MR, Nafissi-Varcheh N (2010) Evaluation of antioxidant properties and total phenolic contents of some strains of microalgae. J Appl Phycol 22:43-50

159. Kepekci RA, Saygideger SD (2012) Enhancement of phenolic compound production in Spirulina platensis by two-step batch mode cultivation. J Appl Phycol 24:897-905

160. Leema JT, Kirubagaran R, Vinithkumar NV, Dheenan PS, Karthikayulu S (2010) High value pigment production from Arthrospira (Spirulina) platensis cultured in seawater. Bioresour Technol 101:9221-9227

161. Reinsvold RE, Jinkerson RE, Radakovits R, Posewitz MC, Basu C (2011) The production of the sesquiterpene beta-caryophyllene in a transgenic strain of the cyanobacterium Synechocystis. J Plant Physiol 168:848-852

162. Wang GS, Grammel H, Abou-Aisha K, Sagesser R, Ghosh R (2012) High-level production of the industrial product lycopene by the photosynthetic bacterium Rhodospirillum rubrum. Appl Environ Microbiol 78:7205-7215

163. Ducat DC, Avelar-Rivas JA, Way JC, Silver PA (2012) Rerouting carbon flux to enhance photosynthetic productivity. Appl Environ Microbiol 78:2660-2668

164. Haase SM, Huchzermeyer B, Rath T (2012) PHB accumulation in Nostoc muscorum under different carbon stress situations. J Appl Phycol 24:157-162

165. Tyo KE, Jin YS, Espinoza FA, Stephanopoulos G (2009) Identification of gene disruptions for increased poly-3-hydroxybutyrate accumulation in Synechocystis PCC 6803. Biotechnol Prog 25:1236-1243

166. Aikawa S, Izumi Y, Matsuda F, Hasunuma T, Chang JS, Kondo A (2012) Synergistic enhancement of glycogen production in Arthrospira platensis by optimization of light intensity and nitrate supply. Bioresour Technol 108:211-21

167. Razon LF (2012) Life cycle energy and greenhouse gas profile of a process for the production of ammonium sulfate from nitrogen-fixing photosynthetic cyanobacteria. Bioresour Technol 107:339-346

168. Carlozzi P, Buccioni A, Minieri S, Pushparaj B, Piccardi R, Ena A et al (2010) Production of bio-fuels (hydrogen and lipids) through a photofermentation process. Bioresour Technol 101(9):3115-3120

169. Chen CY, Yeh KL, Aisyah R, Lee DJ, Chang JS (2011) Cultivation, photobioreactor design and harvesting of microalgae for biodiesel production: a critical review. Bioresour Technol 102(1):71-81

170. Lam MK, Lee KT (2012) Microalgae biofuels: a critical review of issues, problems and the way forward. Biotechnol Adv 30(3):673-690

171. Xu L, Weathers PJ, Xiong XR, Liu CZ (2009) Microalgal bioreactors: challenges and opportunities. Eng Life Sci 9(3):178-189

172. Stephenson AL, Kazamia E, Dennis JS, Howe CJ, Scott SA, Smith AG (2010) Life-cycle assessment of potential algal biodiesel production in the United Kingdom: a comparison of raceways and air-lift tubular bioreactors. Energy Fuel 24(7):4062-4077

173. Rosenberg J, Oyler G, Wilkinson L, Betenbaugh M (2008) A green light for engineered algae: redirecting metabolism to fuel a biotechnology revolution. Biotechnol 19:430-436

174. Ono E, Cuello JL (2004) Design parameters of solar concentration systems for $\mathrm{CO}_{2}$ mitigating algal photobioreactors. Energy 29:1651-1657

175. Christenson L, Sims R (2011) Production and harvesting of microalgae for wastewater treatment, biofuels, and bioproducts. Biotechnol Adv 29(6):686-702

176. Wu Z, Zhu Y, Huang W, Zhang C, Li T, Zhang Y et al (2012) Evaluation of flocculation induced by $\mathrm{pH}$ increase for harvesting microalgae and reuse of flocculated medium. Bioresour Technol 110:496-502

177. Renault F, Sancey B, Badot PM, Crini G (2009) Chitosan for coagulation/ flocculation processes-an eco-friendly approach. Eur Polymer J 45(5):1337-1348

178. de Godos I, Guzman HO, Soto R, García-Encina PA, Becares E, Muñoz R et al (2011) Coagulation/flocculation-based removal of algal-bacterial biomass from piggery wastewater treatment. Bioresour Technol 102(2):923-927

179. Moreno-Garrido I (2008) Microalgae immobilization: current techniques and uses. Bioresour Technol 99(10):3949-3964
180. Moreira SM, Moreira-Santos M, Guilhermino L, Ribeiro R (2006) Immobilization of the marine microalga Phaeodactylum tricornutum in alginate for in situ experiments: Bead stability and suitability. Enz Microbiol Technol 38(1):135-141

181. Ertuğrul S, Bakır M, Dönmez G (2008) Treatment of dye-rich wastewater by an immobilized thermophilic cyanobacterial strain: Phormidium sp. Ecol Eng 32(3):244-248

182. Guedri H, Durrieu C (2008) A self-assembled monolayers based conductometric algal whole cell biosensor for water monitoring. Microchim Acta 163(3-4):179-184

183. Mallick N (2006) Immobilization of microalgae. In Immobilization of Enzymes and Cells (pp. 373-391). Humana Press.

184. Pérez-Martínez C, Sánchez-Castillo P, Jiménez-Pérez MV (2010) Utilization of immobilized benthic algal species for $N$ and $P$ removal. J Appl Phycol 22(3):277-282

185. Ruiz-Marin A, Mendoza-Espinosa L (2008) Ammonia removal and biomass characteristics of alginate-immobilized Scenedesmus obliquus cultures treating real wastewater. Fresenius Environ Bull 17:1236-1241

186. Ruiz-Marin A, Mendoza-Espinosa LG, Stephenson T (2010) Growth and nutrient removal in free and immobilized green algae in batch and semi-continuous cultures treating real wastewater. Bioresour Technol 101(1):58-64

187. Ranjan A, Patil C, Moholkar VS (2010) Mechanistic assessment of microalgal lipid extraction. Ind Eng Chem Res 49(6):2979-2985

188. Sander K, Murthy GS (2010) Life cycle analysis of algae biodiesel. Int J Life Cycle Assess 15(7):704-714

189. Rawat I, Ranjith Kumar R, Mutanda T, Bux F (2011) Dual role of microalgae: phycoremediation of domestic wastewater and biomass production for sustainable biofuels production. Appl Energy 88(10):3411-3424

190. Amaro HM, Guedes A, Malcata FX (2011) Advances and perspectives in using microalgae to produce biodiesel. Appl Energy 88(10):3402-3410

191. Lee J-Y, Yoo C, Jun S-Y, Ahn C-Y, Oh H-M (2010) Comparison of several methods for effective lipid extraction from microalgae. Biores Technol 101:575-577

192. Young G, Nippgen F, Titterbraudt S, Cooney MJ (2010) Lipid extraction from biomass using co-solvent mixtures of ionic liquids and polar covalent molecules. Sep Purif Technol 72:118-121

193. Kim YH, Choi YK, Park J, Lee S, Yang YH, Kim HJ et al (2012) lonic liquid-mediated extraction of lipids from algal biomass. Bioresour Technol 109:312-315

194. Pragya N, Pandey KK, Sahoo PK (2013) A review on harvesting, oil extraction and biofuels production technologies from microalgae. Renew Sustain Energy Rev 24:159-171

195. Mendes RL, Nobre BP, Cardoso MT, Pereira AP, Palavra AF (2003) Supercritical carbon dioxide extraction of compounds with pharmaceutical importance from microalgae. Inorg Chim Acta 356:328-334

196. Sawangkeaw R, Bunyakiat K, Ngamprasertsith S (2010) A review of laboratory-scale research on lipid conversion to biodiesel with supercritical methanol (2001-2009). J Supercrit Fluids 55(1):1-13

197. Jaime L, Mendiola JA, Ibáñez E, Martin-Álvarez PJ, Cifuentes A, Reglero G et al (2007) $\beta$-Carotene isomer composition of sub-and supercritical carbon dioxide extracts. Antioxidant activity measurement. J Agric Food Chem 55(26):10585-10590

198. Kitada K, Machmudah S, Sasaki M, Goto M, Nakashima Y, Kumamoto S et al (2009) Supercritical CO2 extraction of pigment components with pharmaceutical importance from Chlorella vulgaris. J Chem Technol Biotechnol 84(5):657-661

199. Macías-Sánchez MD, Mantell Serrano C, Rodríguez Rodríguez M, de la Martínez Ossa E, Lubián LM, Montero O (2008) Extraction of carotenoids and chlorophyll from microalgae with supercritical carbon dioxide and ethanol as cosolvent. J Sep Sci 31(8):1352-1362

200. Ota M, Watanabe H, Kato Y, Watanabe M, Sato Y, Smith RL et al (2009) Carotenoid production from Chlorococcum littorale in photoautotrophic cultures with downstream supercritical fluid processing. J Sep Sci 32(13):2327-2335

201. Ehimen EA, Sun ZF, Carrington CG (2010) Variables affecting the in situ transesterification of microalgae lipids. Fuel 89(3):677-684

202. Zhu LY, Zong MH, Wu H (2008) Efficient lipid production with Trichosporon fermentans and its use for biodiesel preparation. Bioresou Technol 99(16):7881-7885

203. Ziino M, Lo Curto RB, Salvo F, Signorino D, Chiofalo B, Giuffrida D (1999) Lipid composition of Geotrichum candidum single cell protein grown in continuous submerged culture. Bioresour Technol 67(1):7-11 
204. Schuchardt U, Sercheli R, Vargas RM (1998) Transesterification of vegetable oils: a review. J Braz Chem Soc 9(3):199-210

205. Wahlen BD, Willis RM, Seefeldt LC (2011) Biodiesel production by simultaneous extraction and conversion of total lipids from microalgae, cyanobacteria, and wild mixed-cultures. Bioresour Technol 102(3):2724-2730

206. Du W, Xu YY, Zeng J, Liu DH (2004) Novozym 435-catalysed transesterification of crude soya bean oils for biodiesel production in a solvent-free medium. Biotechnol Appl Biochem 40(2):187-190

207. Heeres AS, Picone CSF, van der Wielen LAM, Cunha RL, Cuellar MC (2014) Microbial advanced biofuels production: overcoming emulsification challenges for large-scale operation. Trends Biotechnol 32(4):221-229

208. Zhang S, Bryant DA (2011) The tricarboxylic acid cycle in cyanobacteria. Science 334:1551-1553

209. Steinhauser D, Fernie AR, Araujo WL (2012) Unusual cyanobacterial TCA cycles: not broken just different. Trends Plant Sci 17(9):503-509

210. Deng M-D, Coleman JR (1999) Ethanol synthesis by genetic engineering in cyanobacteria. Appl Environ Microbiol 65(2):523-528

211. Yao L, Qi F, Tan X, Lu X (2014) Improved production of fatty alcohols in cyanobacteria by metabolic engineering. Biotechnol Biofuels 7:94

212. Wang W, Liu X, Lu X (2013) Engineering cyanobacteria to improve photosynthetic production of alka(e)nes. Biotechnol Biofuels 6:69

213. McNeely K, Xu Y, Bennette N, Bryant DA, Dismukes GC (2010) Redirecting reductant flux into hydrogen production via metabolic engineering of fermentative carbon metabolism in a cyanobacterium. Appl Environ Microbiol 76(15):5032-5038

214. Angelmyr SA, Paszota M, Hellingwerf KJ (2012) Engineering a cyanobacterial cell factory for production of lactic acid. Appl Environ Microbiol 78:7098-7106

215. Varman AM, Yu Y, You L, Tan YJ (2013) Photoautotrophic production of D-lactic acid in an engineered cyanobacterium. Microb Cell Fact 12:117

216. Li H, Liao JC (2013) Engineering a cyanobacterium as the catalyst for the photosynthetic conversion of $\mathrm{CO}_{2}$ to 1,2-propanediol. Microb Cell Fact 12:4

217. Guerrero F, Carbonell V, Cossu M, Correddu D, Jones PR (2012) Ethylene synthesis and regulated expression of recombinant protein in Synechocystis sp. PCC 6803. PLoS One 7(11):e50470

218. Sakai M, Ogawa T, Matsuoka M, Fukuda H (1997) Photosynthetic conversion of carbon dioxide to ethylene by the recombinant cyanobacterium, Synechococcus sp. PCC 7942, which harbpors a gene for the ethyleneforming enzyme of Pseudomonas syringae. J Ferm Bioeng 84(5):4343-443

219. Takahama K, Matsuoka M, Nagahama K, Ogawa T (2003) Construction and analysis of a recombinant cyanobacterium expressing a chromosomally inserted gene for an ethylene-forming enzyme at the psbAl locus, J. Biosci Bioeng 95(3):302-305

220. Wang B, Pugh S, Nielsen DR, Zhang W, Meldrum DR (2013) Engineering cyanobacteria for photosynthetic production of 3-hydroxybutyrate directly from $\mathrm{CO}_{2}$. Metab Eng 16:68-77

\section{Submit your manuscript to a SpringerOpen ${ }^{\circ}$ journal and benefit from:}

- Convenient online submission

- Rigorous peer review

- Immediate publication on acceptance

- Open access: articles freely available online

- High visibility within the field

- Retaining the copyright to your article

Submit your next manuscript at $>$ springeropen.com 